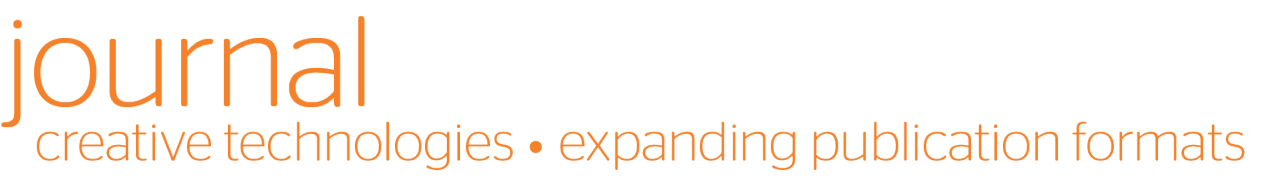

\title{
Impossible Choreographies: the database as a creative tool
}

\author{
Gregory Bennett
}

\begin{abstract}
This exposition discusses the emergence of the database as a creative methodology, and key organising principle in the generation of a series of 3D digital animated artworks. Through detailed explication and demonstration of a complex creative process utilising a range of media formats including video, 3D model views, and interactive 3D, I aim to elucidate an intricate relationship between technology, process and artistic intent, framing this within relevant emergent critical frameworks around digital creative practice. This design strategy will enable the effective communication of some of the inherent qualities of 3D digital production, and the mapping of the operations of the 'database' as a pliable creative tool.

Working directly into high-end 3D modelling and animation software, and taking the actions of a generic male figure as a point of departure, my animations are created in a modular fashion, building up units of performed movements, loops and cycles (both animated and motion-captured), creating a sometimes complex movement vocabulary. This recalls Lev Manovich's notions of the database and the loop as engines of (nonlinear) narrative in digital media work, in particular his principles of modularity, automation and variability as intrinsic to new media objects. In working with complex software tools I also acknowledge in the fabrication process what Rachael Kearney has termed the 'synthetic imagination', and Malcolm Le Grice's conception of submerged authorship in the interaction with the 'intelligent machine' - the creative act as a collaboration with the embodied intellect of the software itself.
\end{abstract}

Drawing on and remediating a range of sources including the photographic studies of Eadweard J. Muybridge, the choreography of Busby Berkeley, nineteenth century optical toys, and the contemporary digital video game, these works present figures which occupy a space between the animate and the inanimate, between automata (devices that move by themselves) and simulacra (devices that simulate other things).

Keywords: $3 D$ animation, digital art, software studies, digital art practice 


\section{Introduction}

This exposition is a reflection on my own art practice as a direct engagement with highend industrial 3D animation software, and of the emergence of the database as a creative methodology, and key organising principle in the generation of a series of 3D digital animated artworks. My adoption of 3D animation software as a primary tool for art practice dates back to 2003-2004 when it became possible to run relatively advanced 3D animation software on a personal computer, and when software packages started to became much more cheaply available. Previous to this accessibility to this kind of three-dimensional computer imaging software was limited, as digital artist Claudia Hart identifies, to 'large corporations or academic institutions' (Hart, 2013, p. 87). Teaching programmes and training courses for programmes such as Autodesk Maya were structured around an 'assembly-line consciousness' (Hart, 2013, p. 93) reflecting 'the production pipelines of multimillion-dollar Hollywood effects films or elaborate shooter games' (Hart, 2013, p. 88), to 'serve mainly as boot camp for the armies of the military-entertainment complex' (Hart, 2013, p. 88).

Models of art practice with new or complex technologies, or challenging multi-medium oeuvres can also involve an artist working with technicians to realise artefacts, 'outsourcing' (Harvey, 2005, p. 15) specialist skillsets. Indeed the maintenance of a 'studio' of assistants to manage challenging production processes or output volumes is one that stretches back to before the Renaissance, with the atelier system, and persists to this day in the studios of high profile practitioners such as Takashi Murakami's Hiropon Factory.

With the current and ongoing exponential rate of change and development of software tools, a 'digital divide' can also arise between those artists engaging directly with digital tools as a consequence of generational familiarity, or conscious adoption of, or adaption to, digital media from pre-digital practice, and those for whom new media tools are beyond more familiar skillsets, or consciously rejected. A similar divide can be observed in the critical appraisal and examination of digitally generated artworks, where a fundamental uncertainty of knowledge of digital production processes might prevail, together with a lack of an as-yet fully developed art-historical aesthetic framework.

Claire Bishop sees 'an entire sphere of "new media" art' which 'rarely overlaps with the mainstream art world', and a generation of high profile artists who are paradoxically 'attracted to the materiality of pre-digital film and photography' perhaps through nostalgia, in her words: 'the passing of real film is a loss to be mourned' (Bishop, 2012). More cynically, perhaps, the easy, unlimited and uncontainable reproducibility of digital formats can be seen to limit digital art's 'commercial viability'.

3D animation as a medium for artistic production may also suffer from a 'guilty by association' status with a predominant Hollywood commercial aesthetic of digital photoreal 'spectacular' visual effects-driven cinematic and gaming product, and a mistrust of post-indexical image-making. Bishop observes that the 'sumptuous texture of indexical media is unquestionably seductive' and that 'the digital, by contrast, is code, inherently alien to human perception. It is, at base, a linguistic model', she says, and she asks: 'Is there a sense of fear underlying visual art's disavowal of new media?' 
(Bishop, 2012). Claudia Hart echoes Bishop in her assertion that:

this technology is alien and remains a challenge conceptually, because it represents a distinct break from the analogical, photographic model of representation that has been the cultural standard since the nineteenth century...3D animation is truly "postphotographic," and as such it is still little understood both inside and outside the art world. (Hart, 2013, p. 88)

My own trajectory of engagement with 3D computer-generated imagery (CGI) was driven by a desire to engage directly with the software interface itself as an artist, to explore ways of harnessing the technology idiosyncratically in the service of a personal rather than corporate vision. As such I would situate my practice within a community of practice identified by Rachel Clarke, Claudia Hart and Michael Rees as the 'RealFake' elucidated in the 2011-12 conference, exhibition and online catalog The Aesthetics of the Fake (Hart, Clarke, \& Rees, 2011). My video works Utopia 1 (2011 HD video with stereo sound, 10:32 minutes) and Utopia II (2012 - HD video, 10 minutes) were subsequently included in the exhibition The Real-Fake: Simulation Technology After Photography (2012) curated by Rachel Clarke and Claudia Hart.

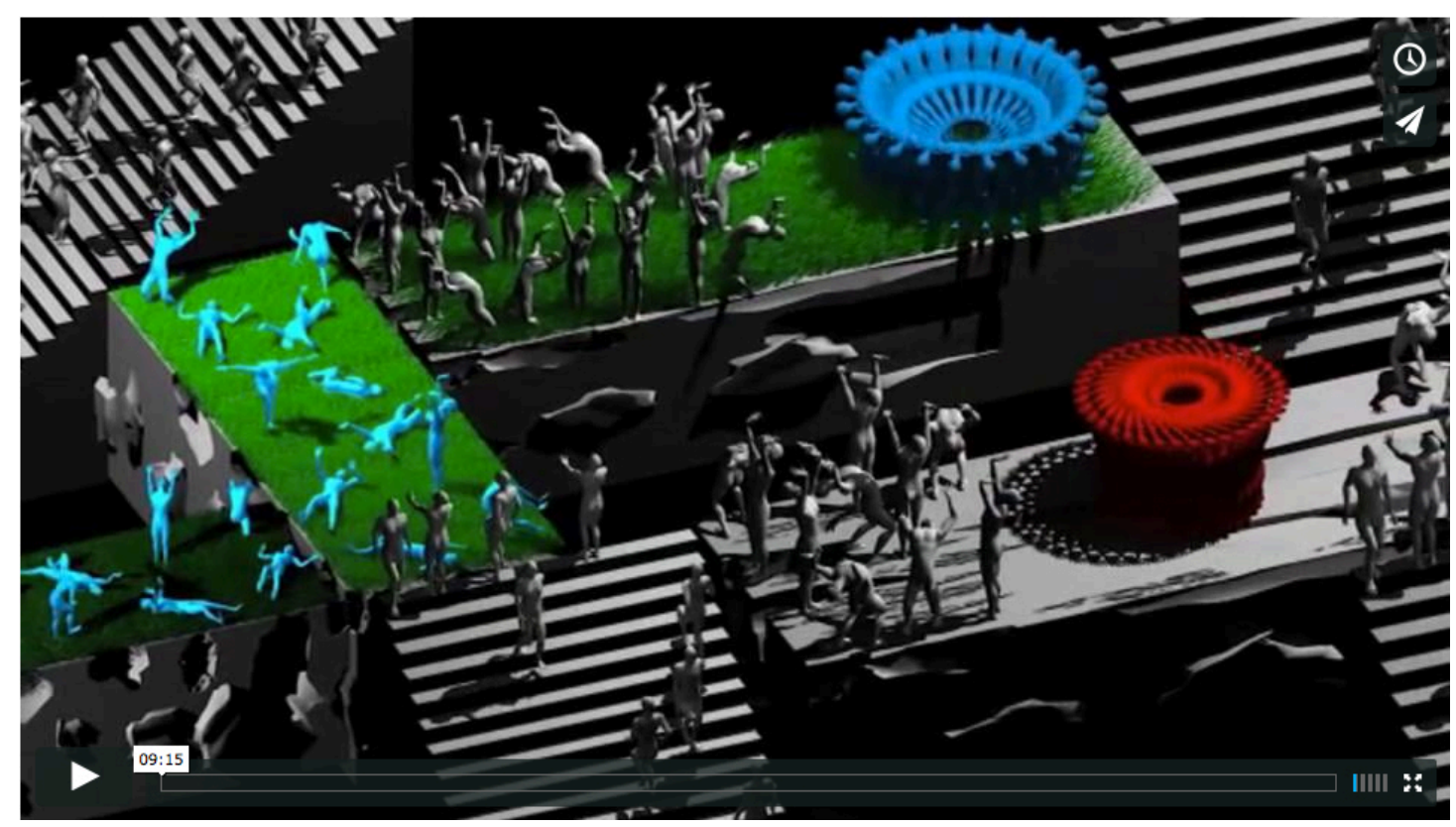

Figure 1. Utopia I (2011) 


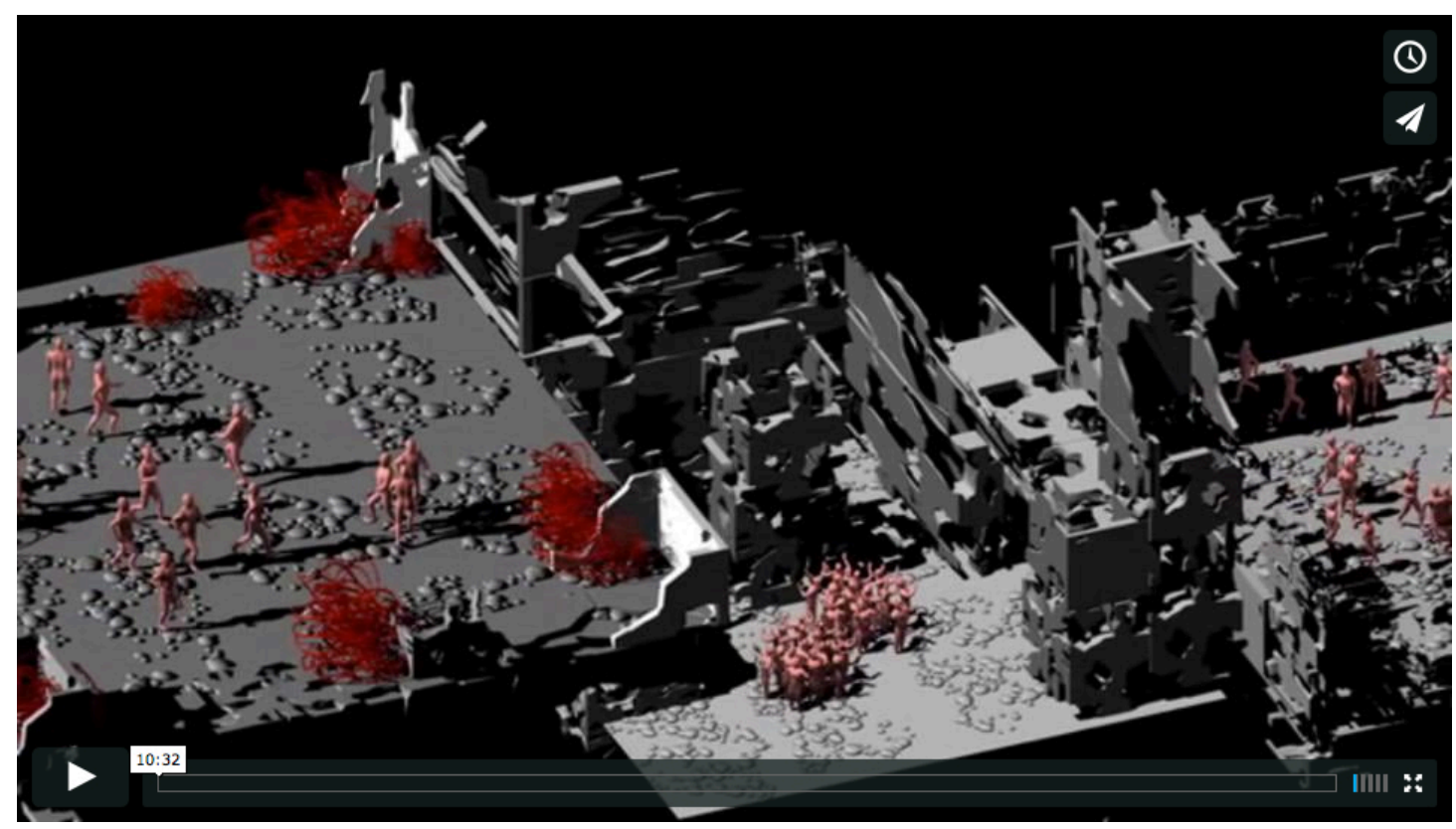

Figure 2. Utopia II (2012)

Clarke, Hart and Rees identify this practice as:

....artists exploring artificial xyz space, the non-referenced synthetic image or object, and the specific qualities of the virtual camera that records it. Its purpose is to position $3 D$ computer graphics in the discursive context of contemporary art. The artists ... all use 3D software to create post-photographic cinematography, and all of them self-consciously place $3 D$ within an avantgarde lexicon. Like their predecessors, video artists who adapted TV technologies for artistic use, these artists have adopted the technology employed in 3D shooter games and feature-length Hollywood animation blockbusters, but reject entertainment industry aesthetics and content, instead applying the medium to the trajectory of art history. (Hart \& Clarke, 2012)

They also identify that a 'common strategy is to isolate and define a formal language native to the virtual' (Hart \& Clarke, 2012). This forms the basis of this discussion and reflection on my own digital practice.

This study will draw on a decade of work: from my first 3D digital works in 2004 to 2015. It will attempt to trace some consistencies in the relationship between technology, process and artistic intent, framing this within relevant emergent critical frameworks around digital creative practice. This strategy aims at effectively communicating of some of the inherent qualities of 3D digital production, and the mapping of the operations of the 'database' as a pliable creative tool.

\section{D animation as a tool for art practice}

I utilised 3D animation software for an ongoing series of moving image works that explore intricately constructed virtual worlds populated by multitudes of deindividualized moving figures trapped in a form of uncanny life: bodies enacting a series of seemingly endless cryptic cyclic rituals, existing in a marginal state, neither dead nor undead. 
Here the corporeal body is transformed into proliferating avatars inhabiting a range of environments where existence is either tenuous, or wholly subsumed into a synthetic ecosystem. These spaces can be read as a series of psychological landscapes, as representations of hermetic digital colonies - depictions that fluctuate between the utopian and dystopian, or as figures enacting some enigmatic ceremonial. The work draws on and remediates a range of representational traditions and influences from both art historical, moving image and popular culture sources where the multiplied body forms the primary subject, including: the photographic studies of Eadweard J. Muybridge; the choreography of 1930's Hollywood choreographer Busby Berkeley; nineteenth century optical toys; and the contemporary digital video game. These works present figures which occupy a space between the animate and the inanimate, between automata (devices that move by themselves) and simulacra (devices that simulate other things).

The fabrication of these works may seem to be taking a meta-creational approach, which might at times appear to mimic the appearance of a living system, but it is also dependent on a range of virtual processes and simulations. This provides a staging ground for a variety of both passive and active interactions between the figures and a range of geographic and architectural settings.

Time and space are ambiguous factors here. Environments rotate or pan past the viewer situated in a kind of metaphysical 'no-space' reminiscent of a video game environment. Figures, objects, and 'natural' phenomena move in synchronous and asynchronous time loops, intervals, and durations, both moving forward and held in a kind of dynamic stasis. The distortions of one-point perspective are rejected. Perspectival space is flattened out to orthographic projection, recalling the representational systems employed in Japanese art and architectural drawings.

Conventional cinematic language and narrative are also eschewed. The grammar of continuity-style editing and cinematic montage is replaced by long continuous shots in looped playback, without any recourse to cutting or transitions. What Malcolm LeGrice identifies in linear narrative cinema as a 'singularly of resolution' where a 'sequential structure is cumulative within codes of dramaturgy' (Le Grice, 2001, p. 241), is also rejected in embracing a temporal approach based on 'The Loop as Narrative Engine' - a term which Lev Manovich has coined in relation to the creative capabilities and potentials of digital media software to 'generate, organise, manipulate, and distribute data' (Manovich, 2001, p. 314).

In retracing the fabrication process of these works, I also became interested in how the image making process could be characterised as a creative interface between artist and complex software, raising the question: how might the practical interaction with digital authoring tools impact the rendition of a final work? Digital moving image making tools offer infinite possibilities for image generation and manipulation. The creative relationship between artist and software can be seen as increasingly requiring a series of negotiations between:

- the possibilities of unlimited potential and the need for productive boundaries and constraints; and 
- the lure of the generic and the predetermined versus the challenge of the original and the particular.

As my awareness grew of the potential influence of the underlying structures of the digital tool itself, I also came to consider the possibility of the creative process as an interaction or even collaboration with the software tools I was utilising. In this, I am recalling LeGrice's conception of 'The intelligent machine', whereby the working with digital software as a 'sophisticated form of the embodiment of intellect' can make it "more difficult to trace the responsibility or "centre of authorship" for any product. Authorship becomes submerged in the cultural artefact produced in dialogue with the intelligent machine' (Le Grice, 2001, p. 240).

These tools provide a range of standard, automated and preset options, but also allow for complex 'under the hood' modification of media. My works are created using the off-the-shelf program Autodesk Maya, an industry-standard software package that is used for 3-D modelling, animation, simulation, and rendering. Widely employed in television and feature film animation, and visual effects and gaming, it features a design ethos which drives aesthetic outcomes ranging from polished graphic animation to photo-realistically rendered simulations, as such capable of fulfilling the high production values required of an array of mainstream moving image product.

As an artist, I was instantly struck by the possibilities of this medium - particularly its ability to create a fully realised and navigable 3D 'world', and its as-yet unrealised potential as an expressive artistic tool beyond the commercial and aesthetic imperatives of mainstream entertainment.

It takes some time and expertise to master Autodesk Maya, even its basic workflow. Animation is also intrinsically time-consuming work. My intention was to generate a relatively large quantity of 3-D animations in my ongoing practice. I wanted:

- to develop ways to work directly and fluidly with the software;

- to be able to create and see results quickly, in pace with the generation of my ideas; and

- to inscribe directly into the software without recourse to typical animation or visual effects industry planning pipelines, which traditionally follow a linear flow from preproduction (script, storyboard, animatic/previsualisation), to production (animation), and post-production (final rendering).

Originally this meant conceiving the works according to the limitations of my current expertise with the software interface, and with some calculated conjecture: making use of the constraints and freedoms of the automated, the pre-set and the default in settings and operations, while seeking ways to configure these according to my creative intentions.

Emerging studies in software and the user-interface are useful in framing and reflecting on my attempts to engage with a software package such as Autodesk Maya as a primary tool for artistic practice. Building on LeGrice's conception of 'submerged authorship' in the interaction with the 'intelligent machine' (Le Grice, 2001, p. 240), and Lev Manovich's discussions around the 'Database' and the 'Loop' (Manovich, 2001) as intrinsic to narrative forms in new media, I also found resonance in Aylish Wood's 
study of the Autodesk Maya software interface where the 'user interface is analysed as a relay of interactions between a surface of toolset menus and the deeper algorithmic structures where data is processed' (Wood, 2015). She identifies an inherent 'tension' in the way Maya's user-interface includes both a viewport, which recreates and presents a recognisable virtual 3D space where elements can be created and manipulated directly in a relatively intuitive way 'as shapes moving in space and time', and a range of dialog boxes, drop-down menus and windows which present the same 3D elements as 'packages of data', which more accurately present and expose the underlying algorithmic systems of the software itself. She states that the 'presence of both persuasive processes creates a tension that establishes the operational logic of the software: creative work in the context of an automated system' (Wood, 2015).

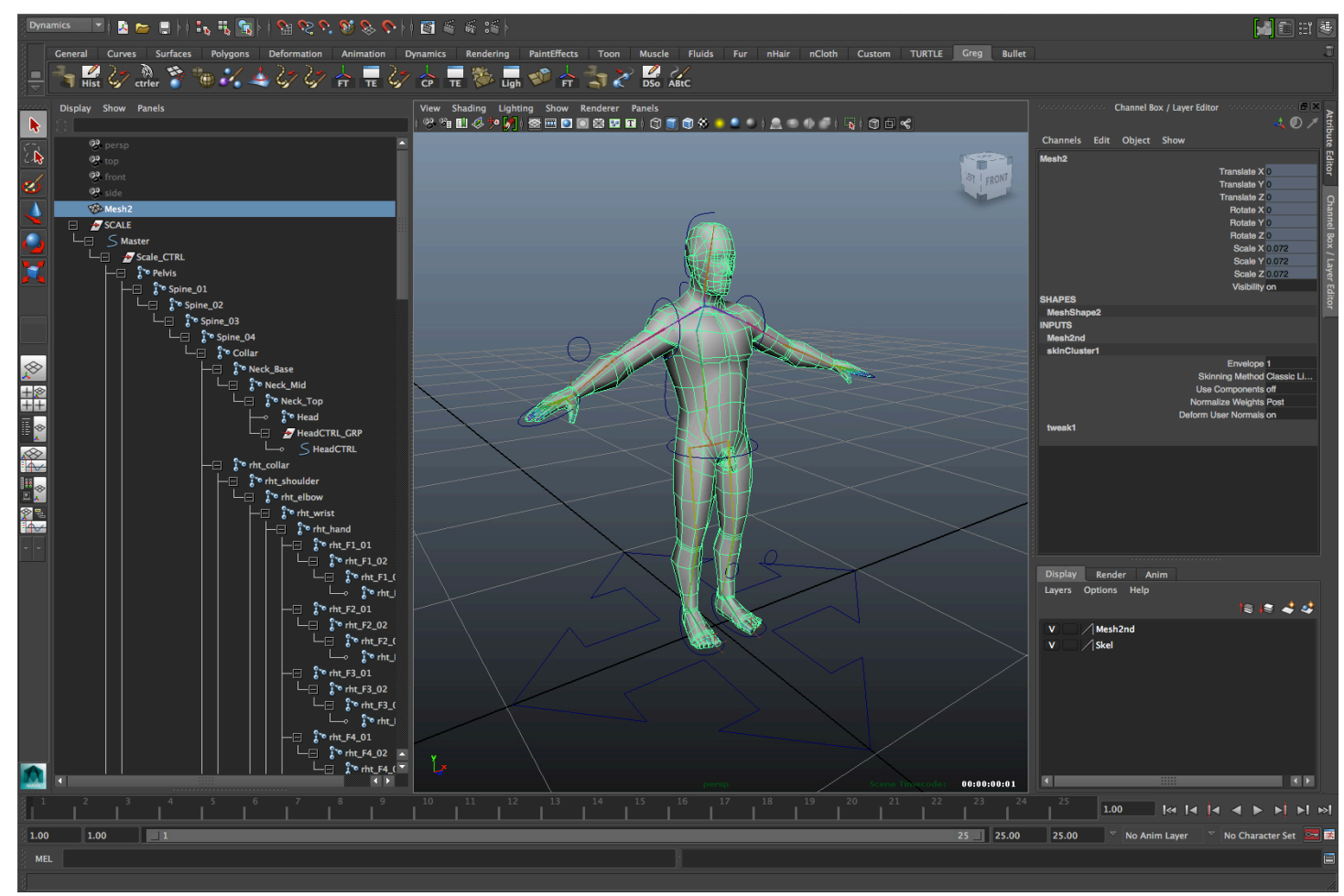

Figure 3. The Maya user-interface with the viewer window in the centre showing a 3D virtual space, surrounded by windows and menus displaying the scene in data form.

Similarly I see Lev Manovich's identification of principles inherent to new media artefacts and their creation, in particular 'Modularity', 'Automation' and 'Variability' (Manovich, 2001) which operate as intrinsic conditions both to influence and enable the conception and fabrication process.

In reflecting on the production process undertaken in the construction of my animations, I recognised how pervasive these principles were in structuring these works. A pattern of data creation, the construction of discreet modular units which can then have automated functions assigned to them, and then the variable organisation and re-organisation of either elements within the frame, or of units of animation within a sequential flow, was invariably followed. The form of the works could be seen to reflect the engagement with processes inherent in functions of the 'machine' - both a creative manipulation and a demonstration of its functionality. 
Manovich quotes Will Wright (author of the Sim games) in regard to the game user experience:

playing the game is a continuous loop between the user (viewing the outcomes and inputting decisions) and the computer (calculating outcomes and displaying them back to the user). The user is trying to build a mental model of the computer model. (McGowan \& McCullaugh, 1995, p. 71).

The user is seen to be discovering 'the rules that operate in the universe constructed by [the] game', gradually learning its 'hidden logic'. If software user is substituted for game user, a similar connection might be observed. The 'hidden logic' (Manovich, 2001 , p. 222) of a software programme, or the functionality of its user interface becomes, consciously or unconsciously, a strong determinant in influencing the creative process and outcomes. Similarly Wood asserts that the relationship of creative to software tool can be characterised as a user/player relationship, as mastery of the graphical user-interface (the viewport) extends through 'play' into the deeper 'rules' structures and operations in the abstract realm of the algorithm (datasets), reflected in the co-existence of these components in the user-interface (Wood, 2015).

Thus a number of questions arise in reflecting on my practice: What creative and practical constraints am I working within? What constraints might I need to impose and to what extent am I influenced by the built-in structures of the tool itself? How might I be in control or not of outcomes and how might these be manipulated?

\section{Background to work - from Muybridge to Manovich}

The series of works grew out of an engagement with a fundamental unit of animation - a generic male figure performing a looped walk cycle.

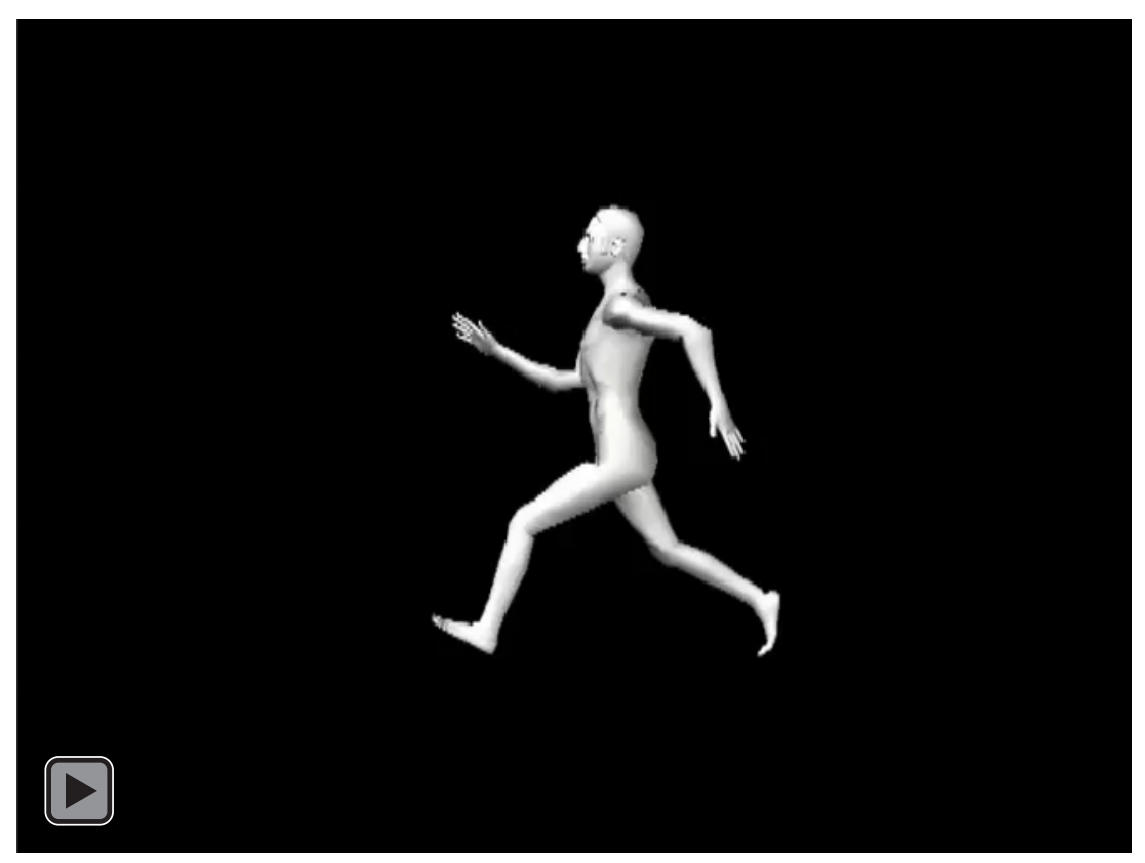

Figure 4. My first 3D animated run cycle from 2004. 


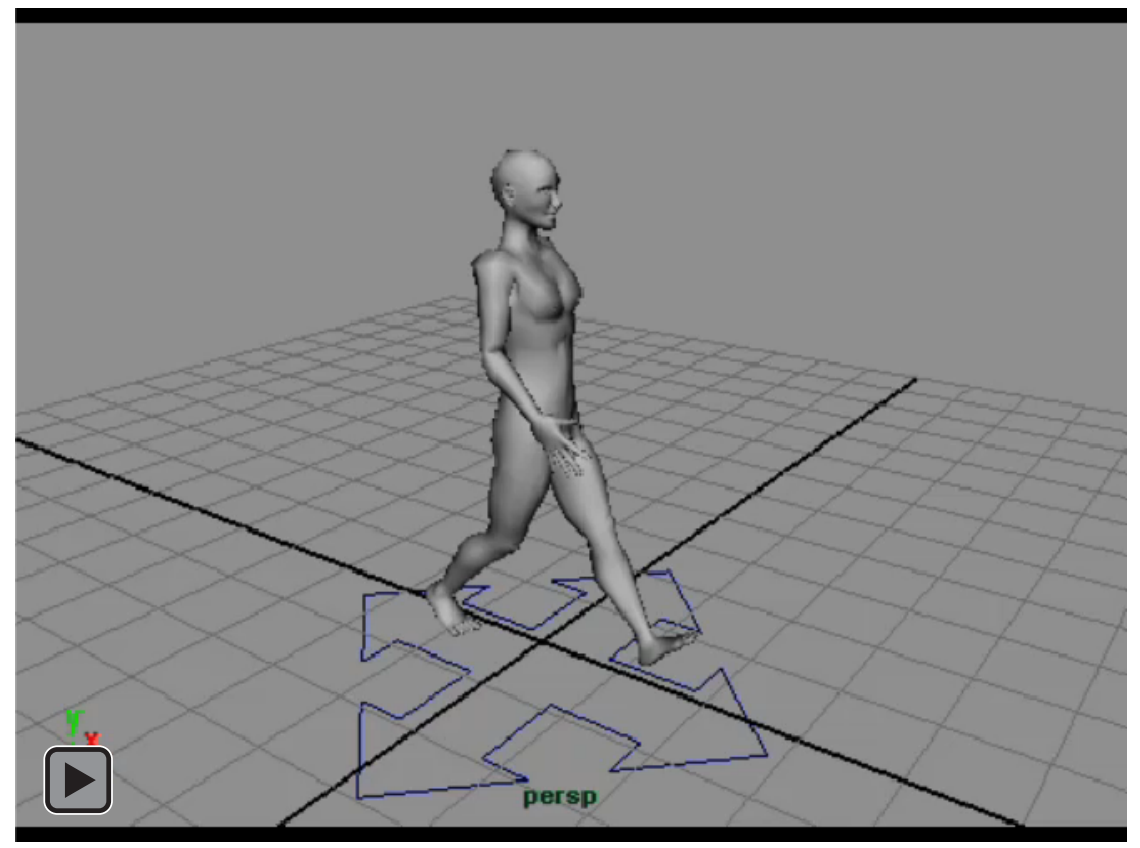

Figure 5. Animated walk cycle in Autodesk Maya's Viewer window.

I see this as an originary image of animation and the recorded moving figure. As a representation, it is a reduction to an essence, a distillation, which can be seen as a signification of the 'animate', and a minimum signification of 'life'. It is also a demonstration of a fundamental skill in the animator's arsenal; it represents the minimal conditions necessary to create the impression of recognisably lifelike human movement. In terms of the economy of animation practice, it is a division, a slice, which can be efficiently duplicated and repeated to create a seamless and potentially endless cycle.

The use of this kind of condensed and standardised depiction of a moving figure inevitably recalls the photographic studies of humans in motion by Eadweard Muybridge, which capture and schematise the moving figure into modular instants.

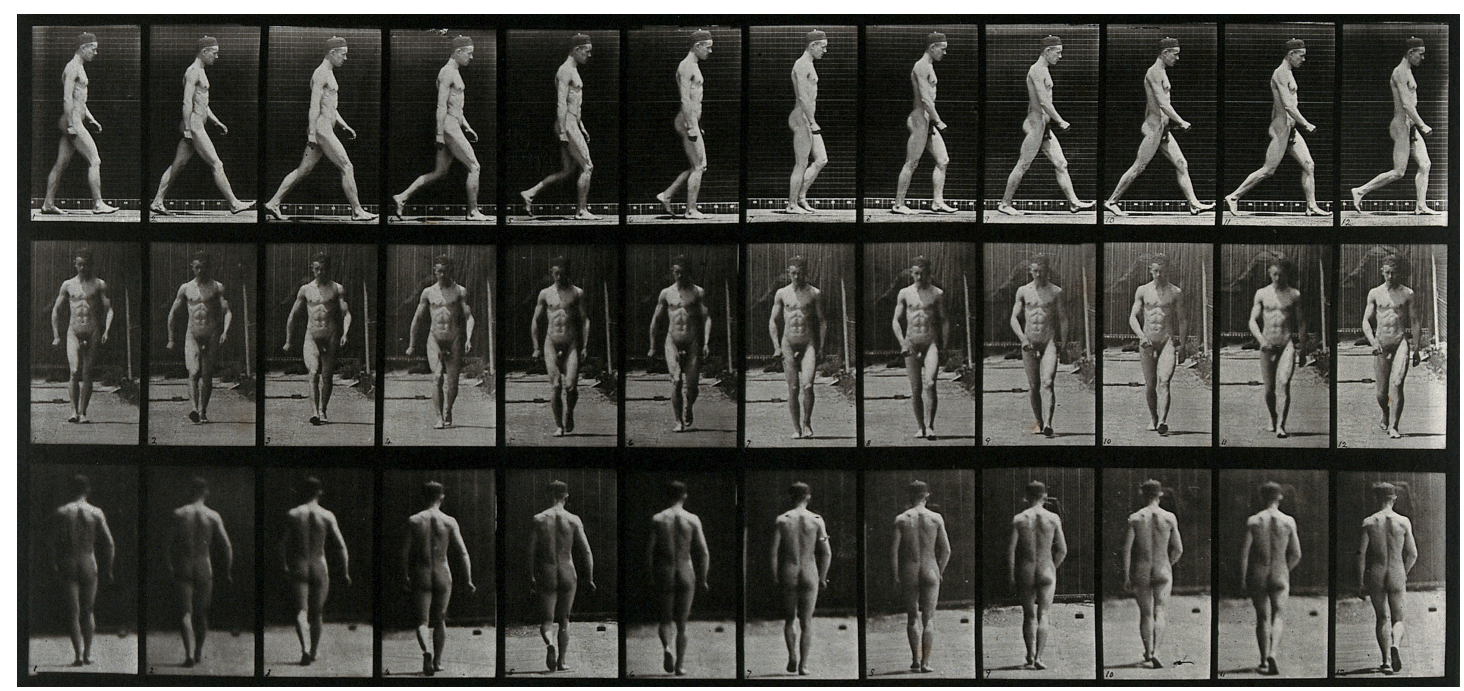

Figure 6. A man walking. Photogravure after Eadweard Muybridge, 1887. Copyrighted work available under Creative Commons Attribution only licence CC BY 4.0 http://creativecommons.org/licenses/by/4.0/ 
Such was the comprehensiveness of Muybridge's studies of humans and animals in motion that they collectively form a valuable database which has long been a useful reference for animators.

Other studies were referenced for particular animated actions also. Here Muybridge's 'Man ascending stairs' (1884-5) is shown from source through to final manifestation in a finished 3D rendered animation.

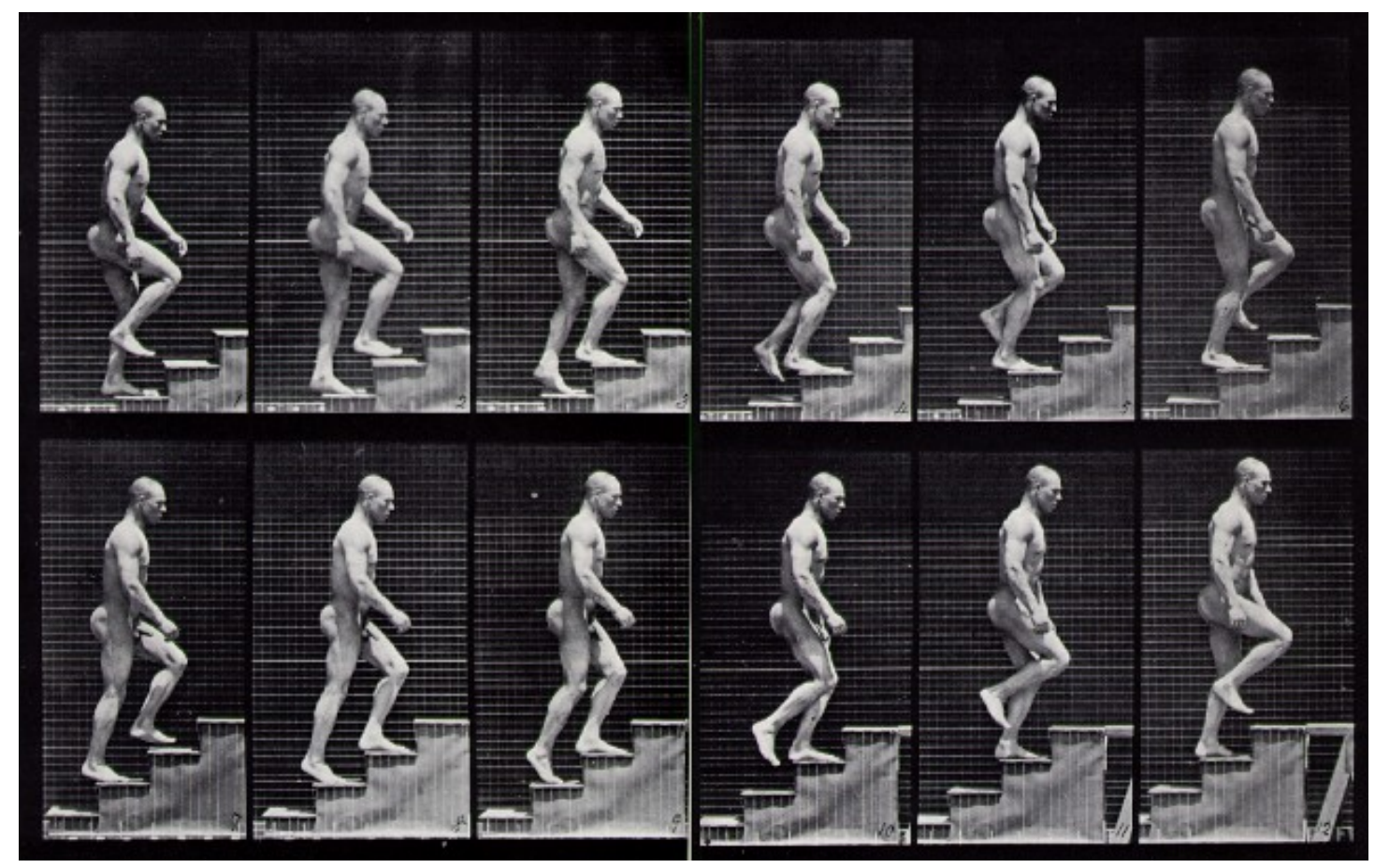

Figure 7. Eadweard Muybridge: Man ascending stairs. 1884-85. (Muybridge, 1884).

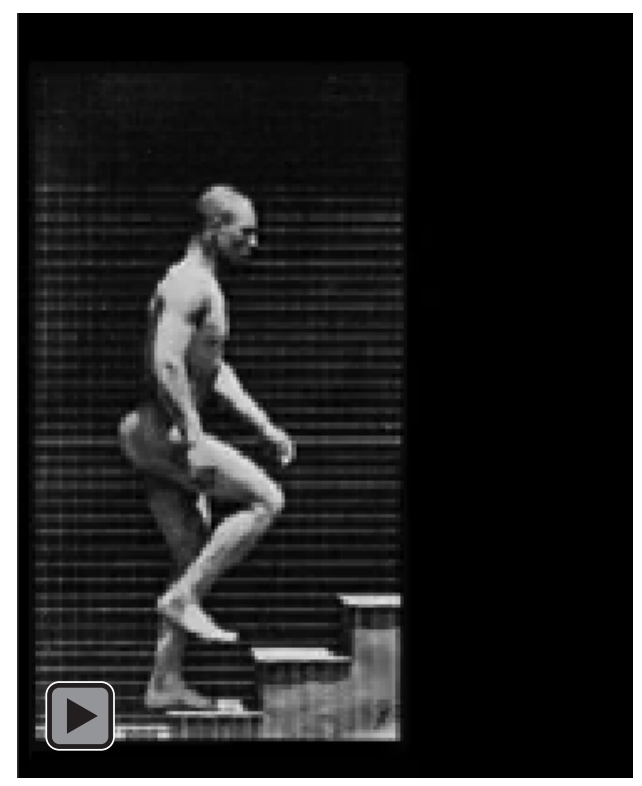

Figure 8. Animated sequence of a man ascending stairs, photos taken by Eadweard Muybridge in 1884-85. (Muybridge, 2004). 


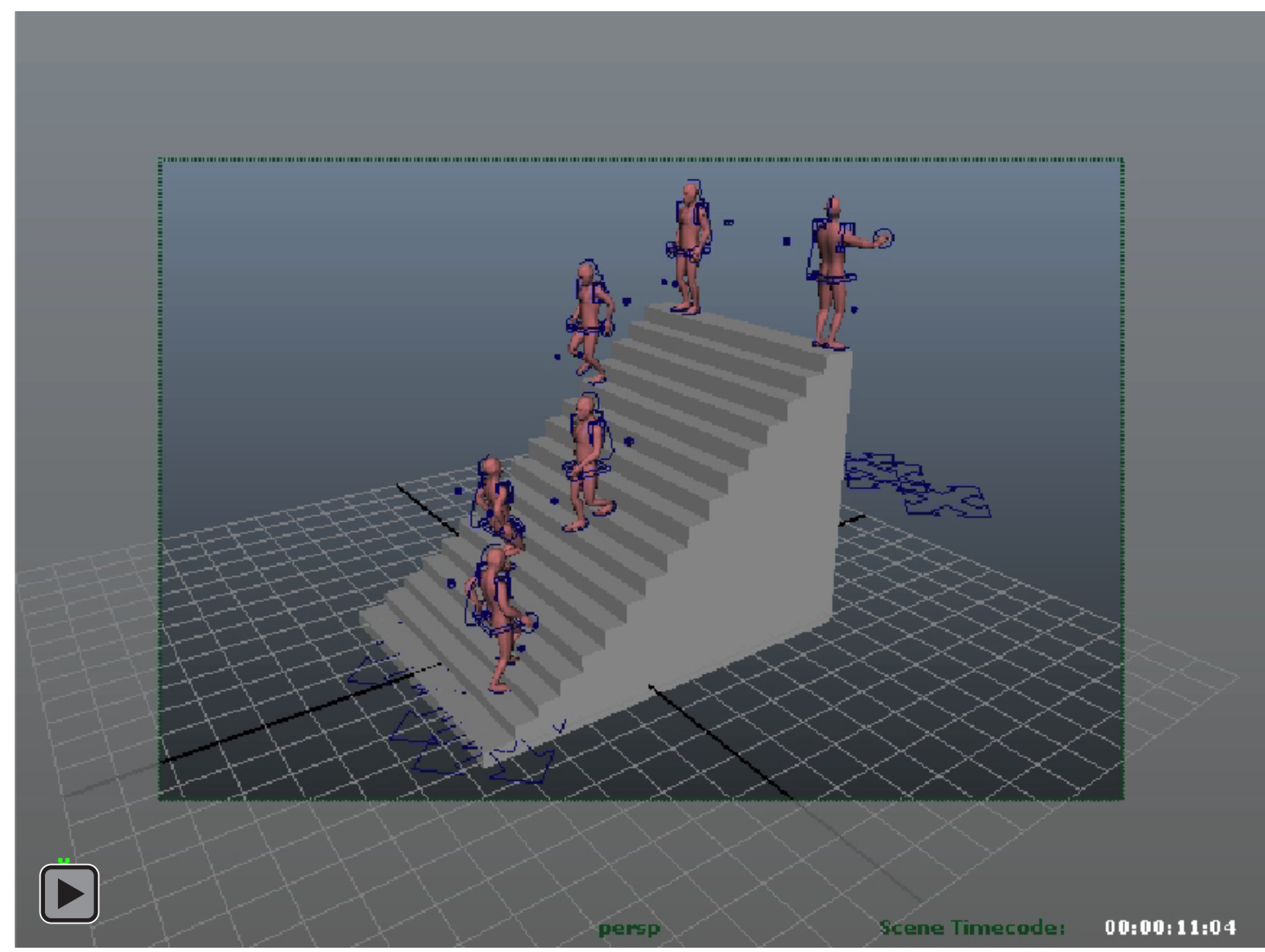

Figure 9. Animated ascending/descending figure is duplicated to create six versions, with each iteration offset spatially and temporally to create variation in their relative position on the 'staircase.

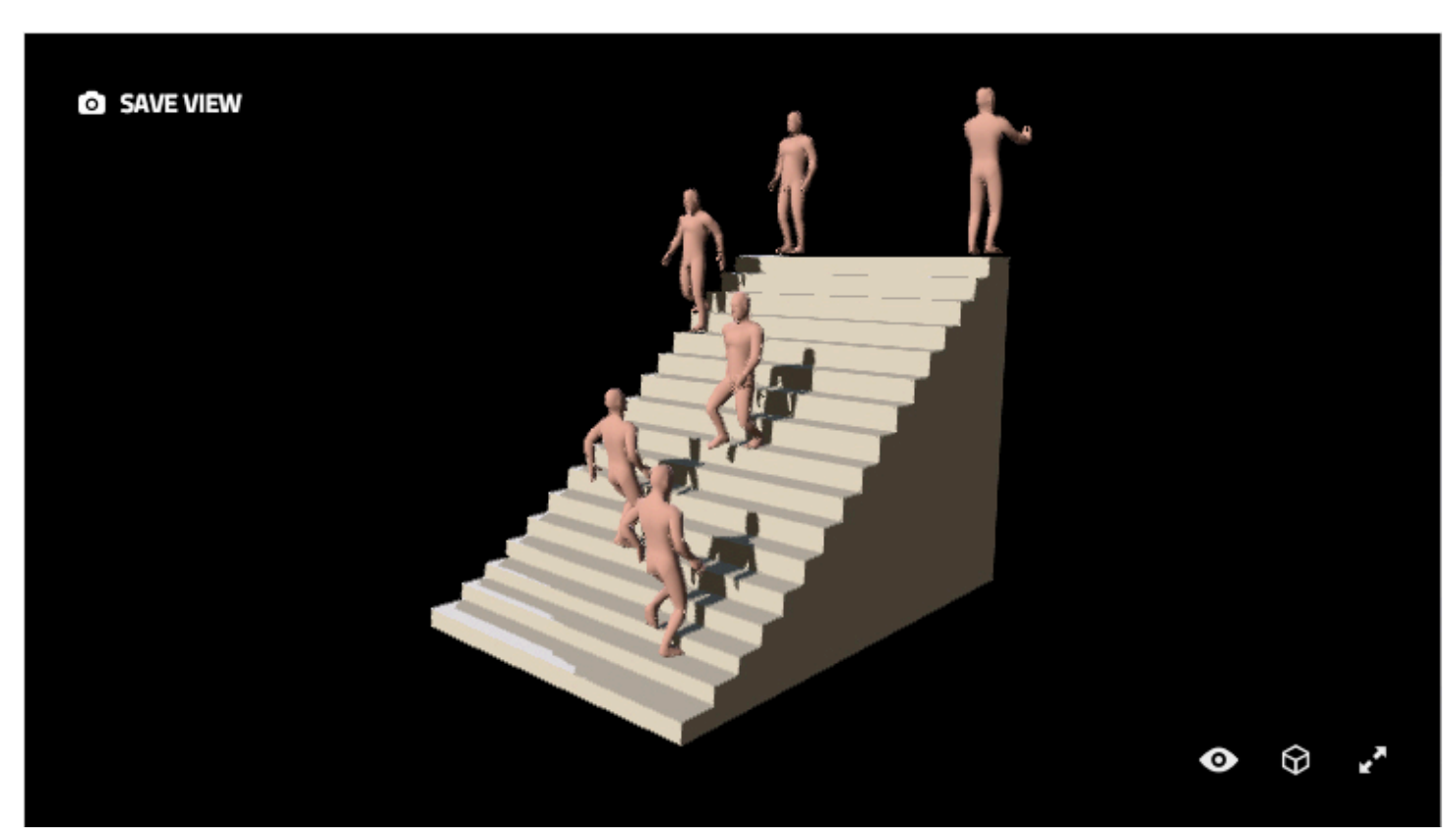

Figure 10. 3D still view of rendered staircase and figures. 


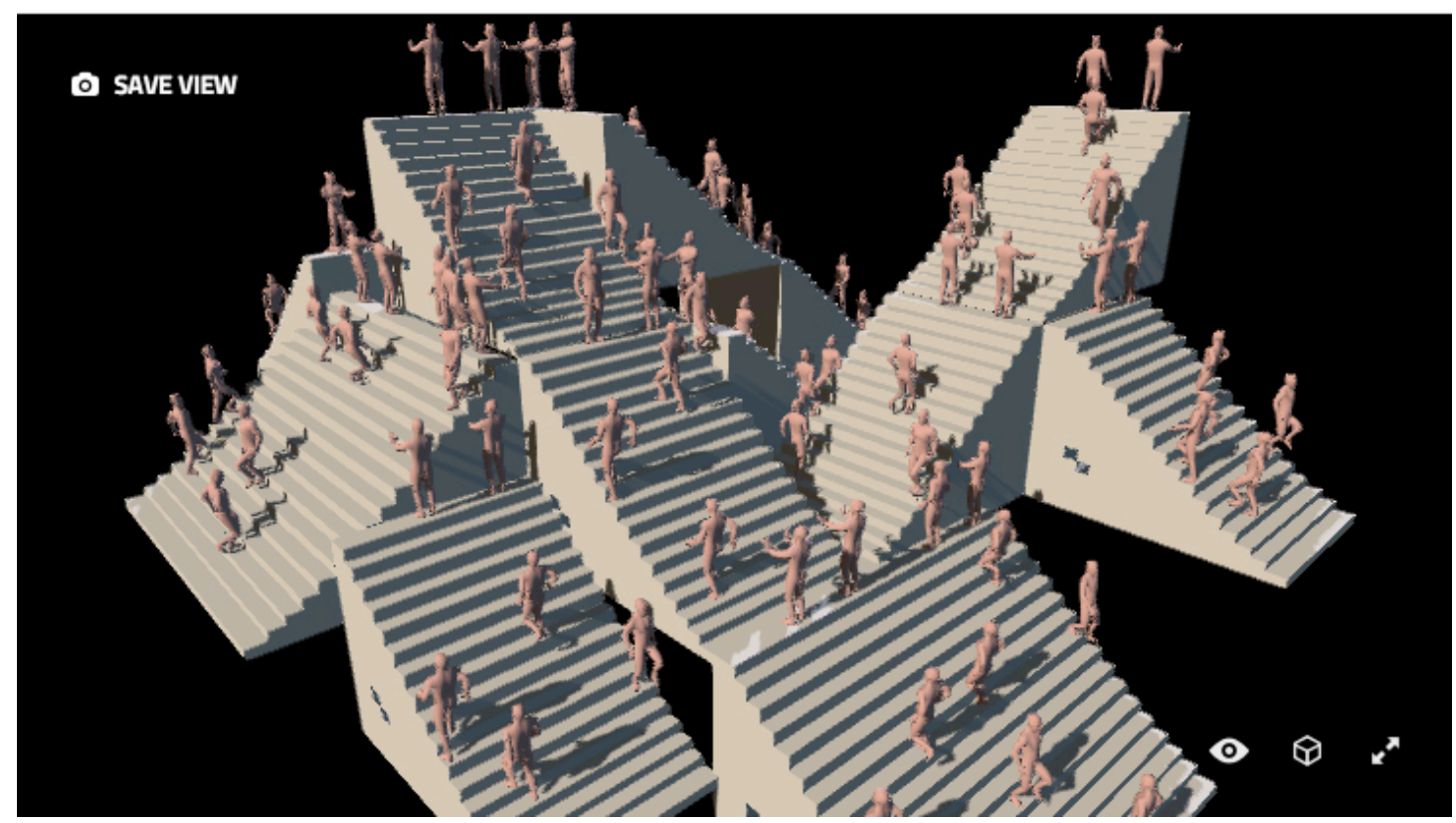

Figure 11. The modular unit of animation can be duplicated multiple times to create a scene.

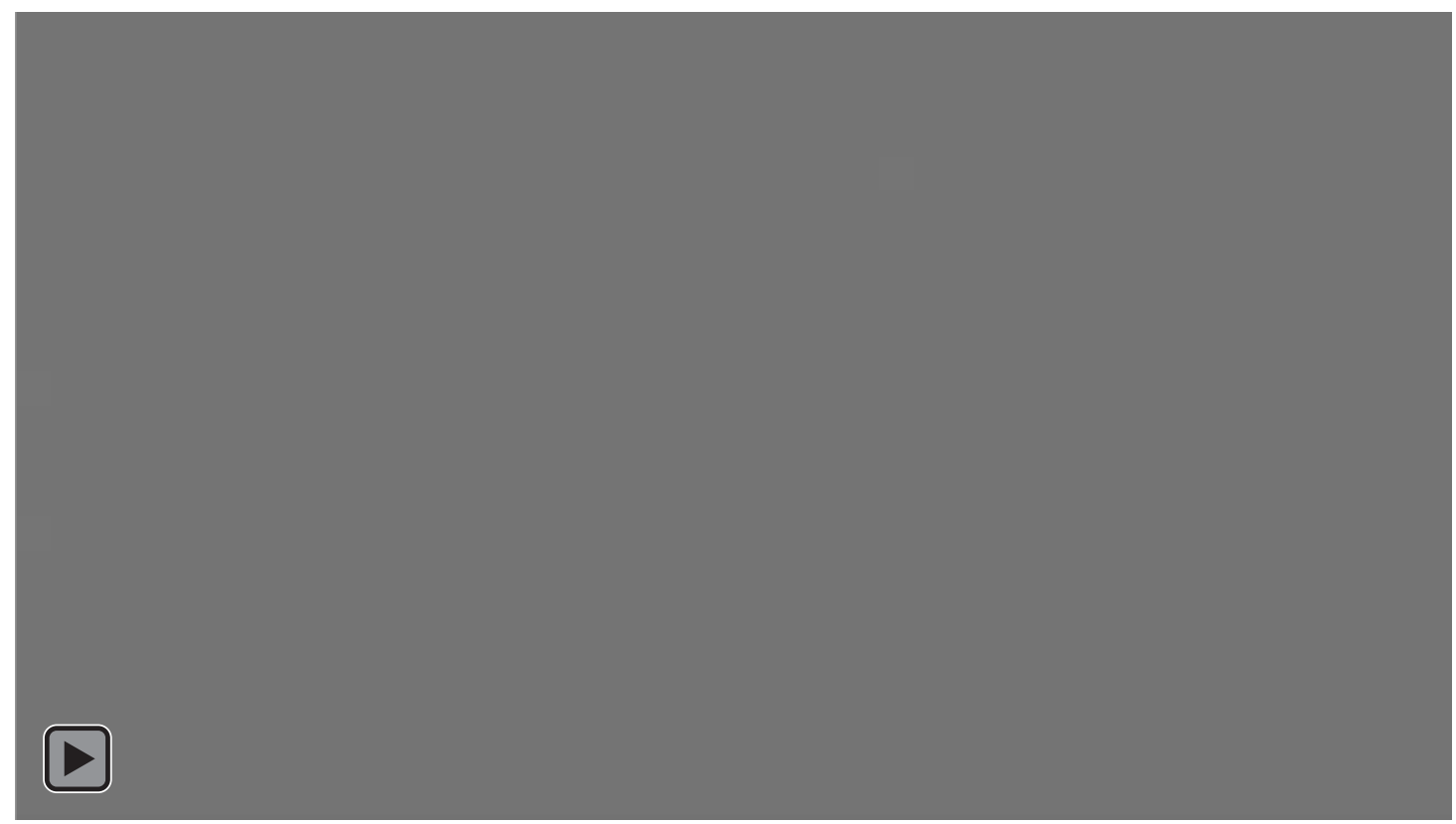

Figure 12. Final render from Apokalypolis I (2013)

Also influential are the looped animations of nineteenth century optical toys, where a linear conception of time is folded into a circle, creating cycles of action which are selfperpetuating and insistent, never achieving resolution, inhabiting a perpetual 'nowtime' which rejects a linear beginning-middle-end progression and resolution. 


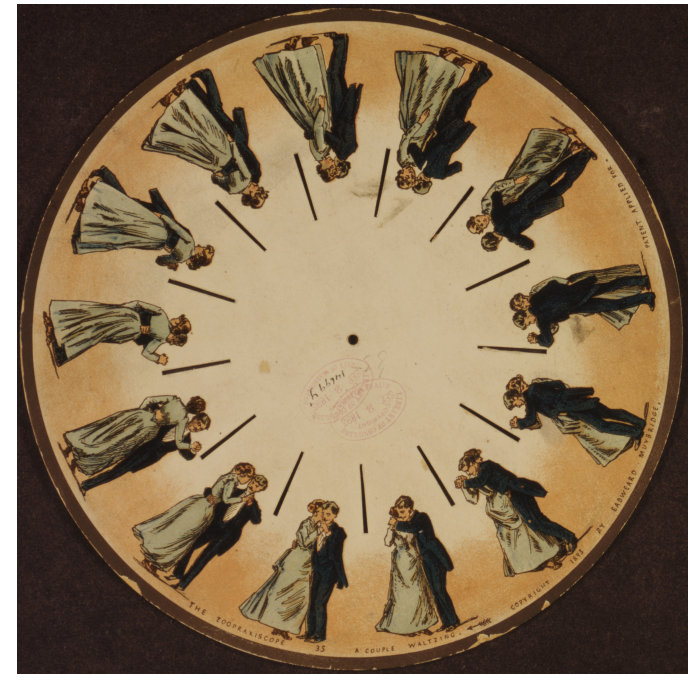

Figure 13. A phenakistoscope disc by Eadweard Muybridge (1893)

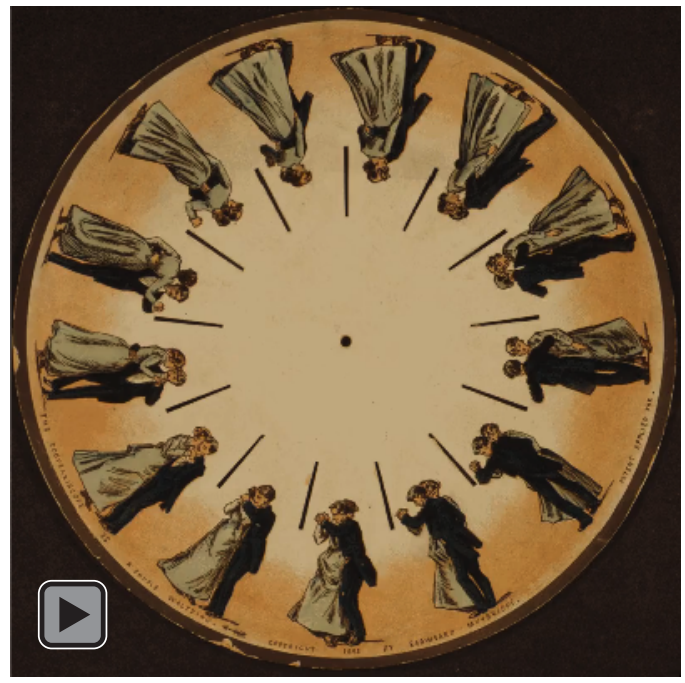

Figure 14. A phenakistoscope disc by Eadweard Muybridge (1893) - animated gif

Lev Manovich states that pro-cinematic optical devices from the phenakistascope to Edison's Kinetoscope, labour-saving techniques in traditional animation, and earlier forms of digital moving image generation from game figures to the Quicktime Player have all employed the loop. It has been associated with temporary technical limitations (for example, of data storage and access) and resists the conventions of linear narrative progression.

The loop is also the basis of programming language which involves the altering of the linear flow of data structures through control structures. It is, in fact, the most elementary form of these structures. This does not, however, negate the possibility of sequential progression. Manovich points out that a 'computer programme progresses from start to end by executing a series of loops' (Manovich, 2001, p. 317). He champions the loop as 'a source of new possibilities for new media' (Manovich, 2001) and conceptualises it as an 'engine' which puts narrative in motion. Loops retrieved from the 'database' are a 'multitude of separate but co-existing temporalities' (Manovich, 2001): units which do not so much replace each other in a ordered flow, but rather are already-activated elements which are composed in one of any possible sequential chains.

LeGrice mirrors this conception in identifying the break with tradition linear and deterministic narrative filmic structures:

Through digital technologies and particularly through the control of image sequence by program, the exercise of alternative structures becomes economically feasible in a way out of the range of traditional film and video technology. The flexibility in structure, the exploration of system and permutation dislodges signification from singular resolution. (Le Grice, 2001, p. 241)

Here we see the model for Manovich's 'database narrative' emerging, and where my own engagement with 3D software starts to be both shaped and creatively enabled by the deep structures of the organisation of the software interface itself, and its patterns of asset creation, storage and retrieval. 


\section{The animated figure - building the database}

The figure was first modelled and given a basic skeletal rig. An unembellished look with regard to its shading and texturing was retained by using default shaders rather than elaborate texture maps.

A key conceptual and practical leap is also the move from $2 D$ to $3 D$, which aligns the creation of imagery for $3 \mathrm{D}$ animation with fabrication rather than drawing, and is thus more akin to sculptural practice. Moving beyond a fixed point of view is required as $3 \mathrm{D}$ elements must be created so they are potentially viewable from all angles.

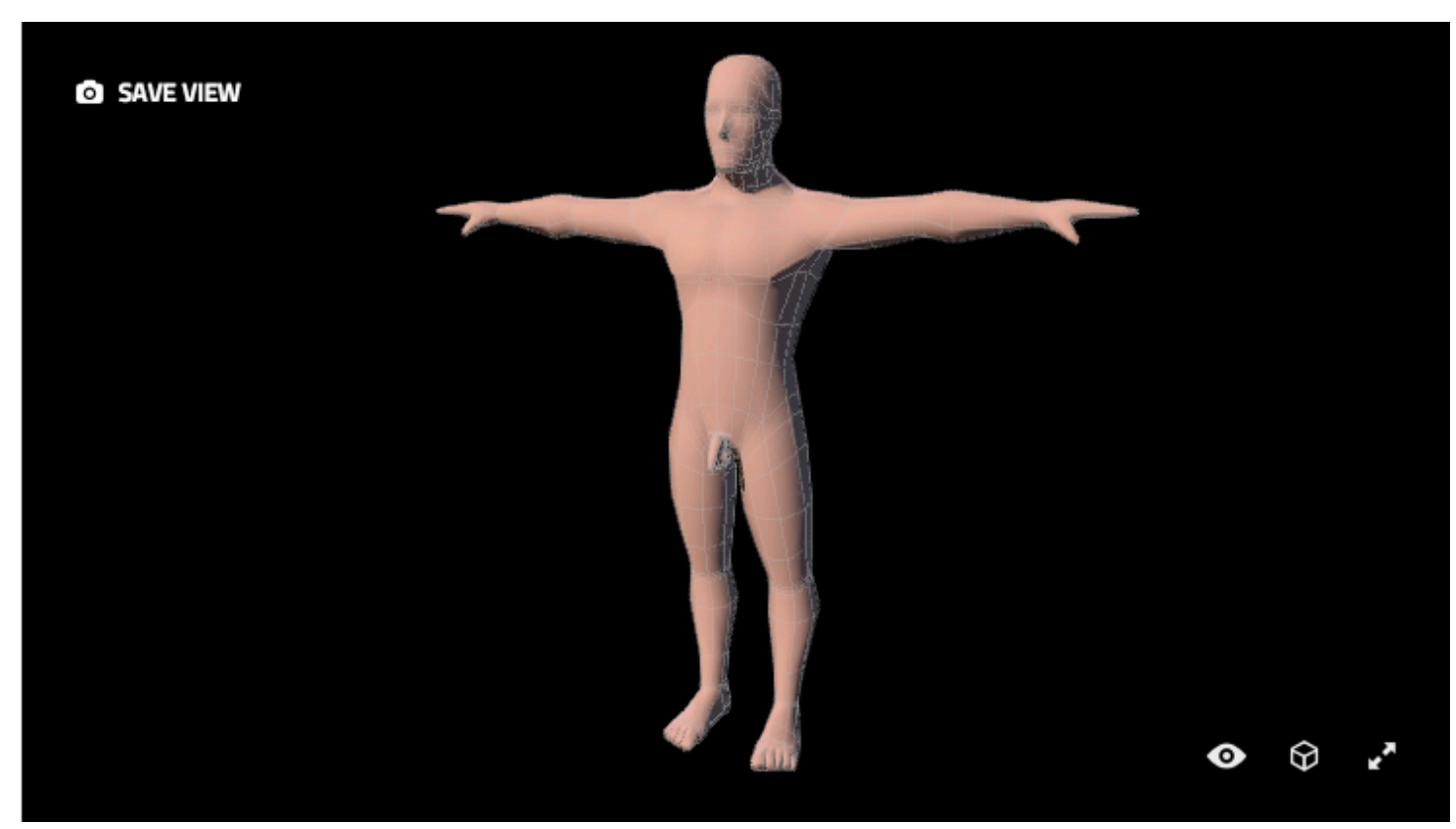

Figure 15. 3D geometric mesh using polygon modelling.

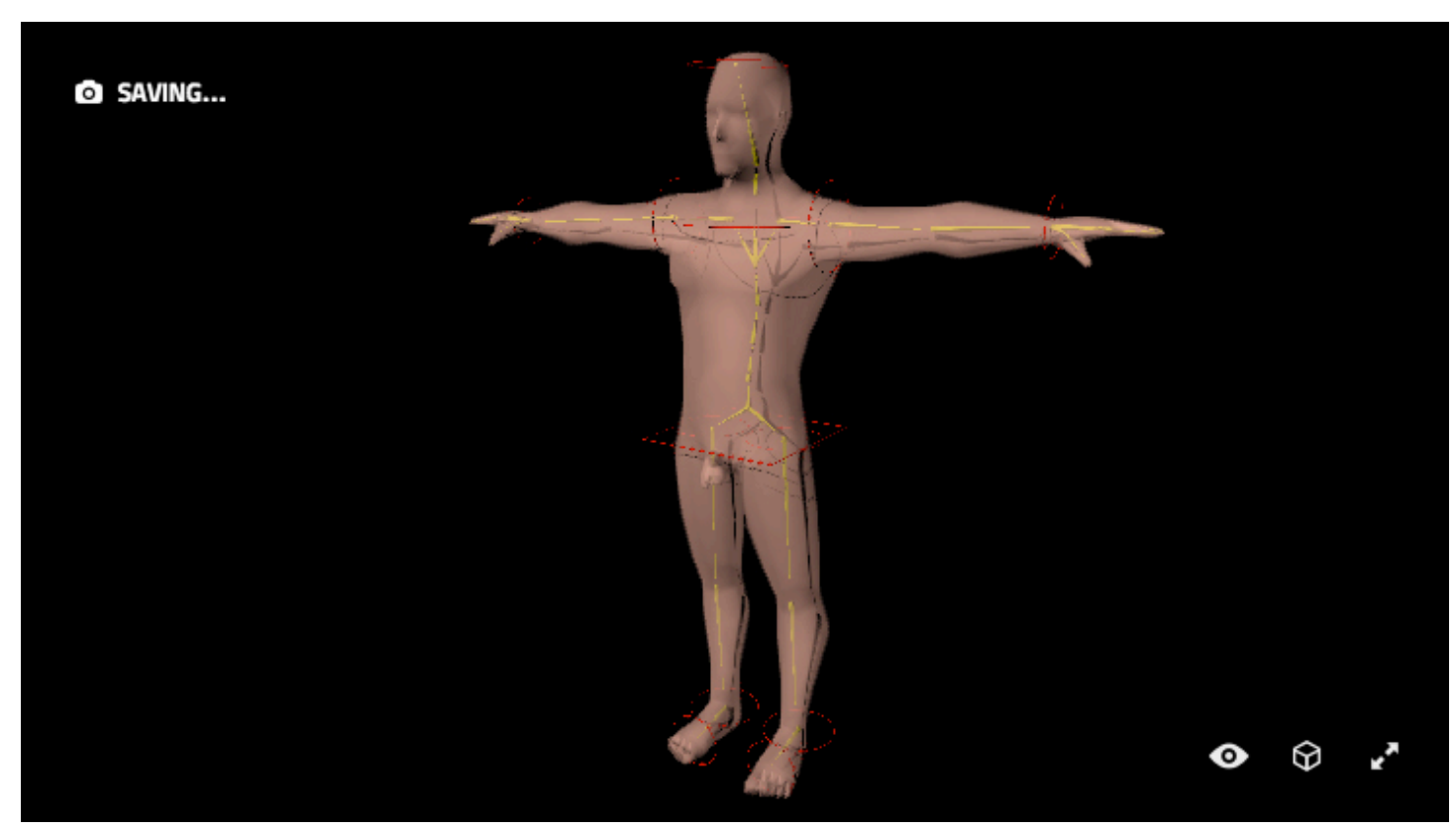

Figure 16. 3D model showing skeleton and animation control rig. 


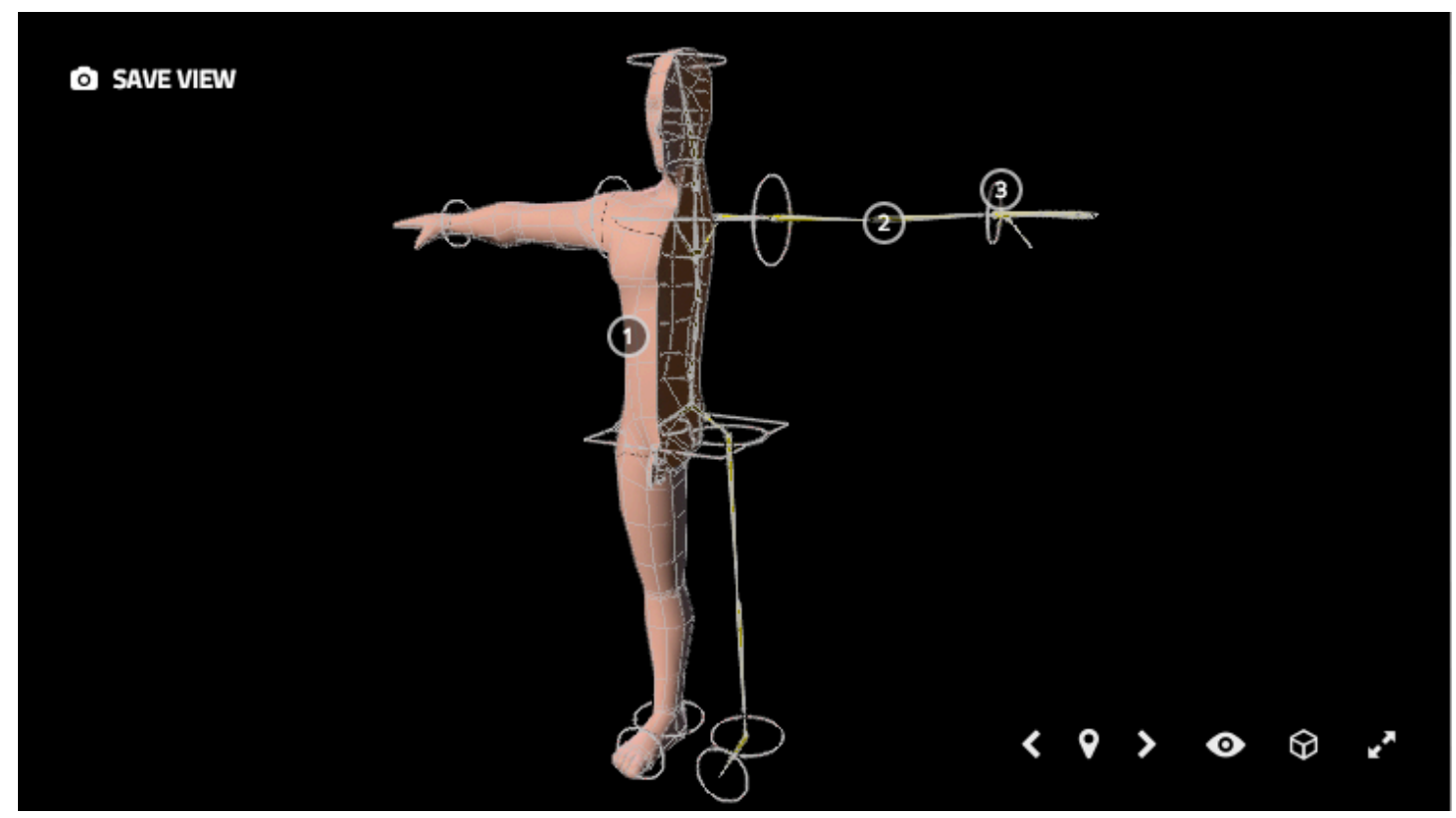

Figure 17. A fully articulated skeletal rig is created to drive the animation of the figure. This can be a partially automated process with Maya's 'Human IK' tool, which generates a fully functional generic skeleton and control rig for bipedal figures.

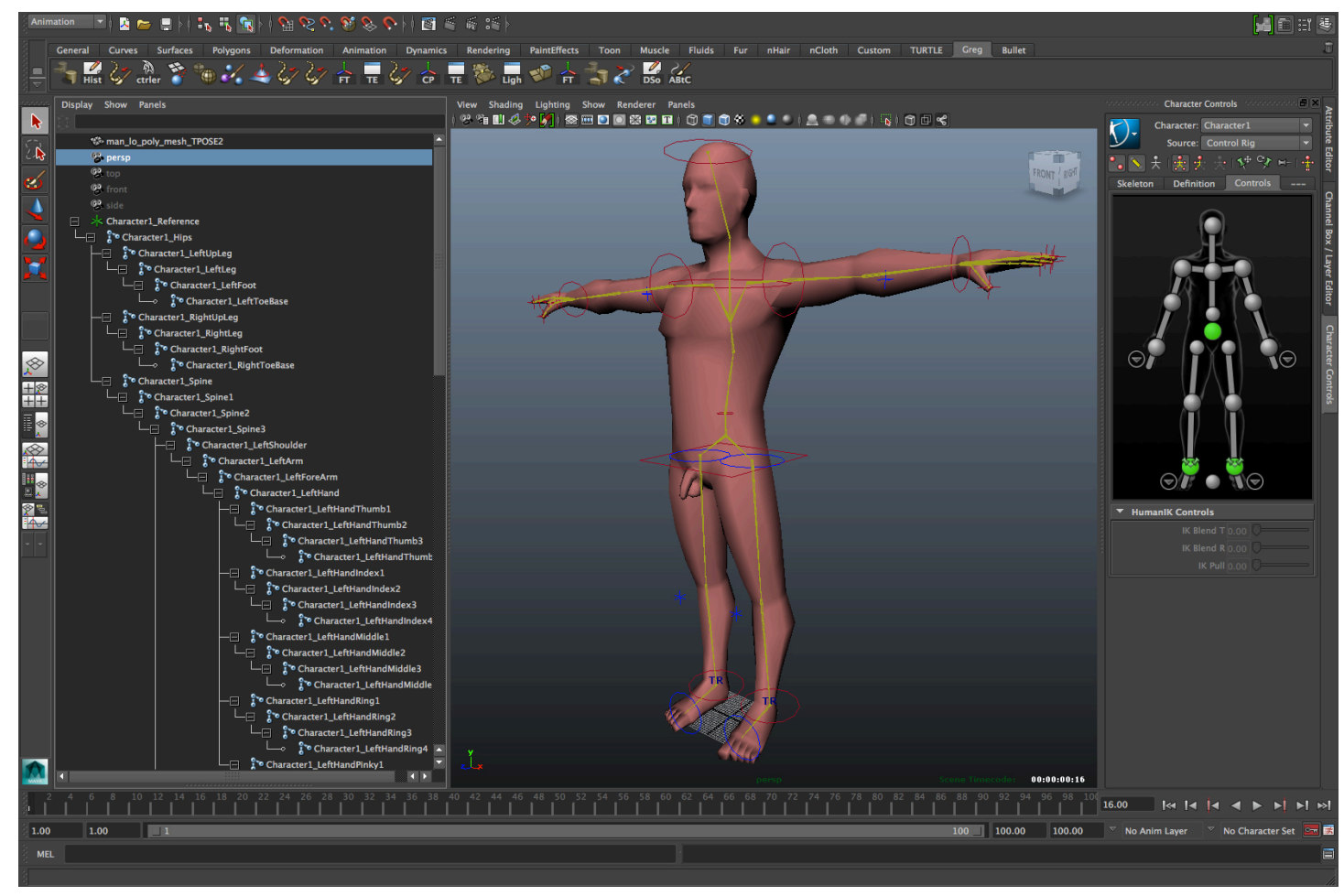

Figure 18. Maya interface showing a fully rigged figure in the centre Viewer window, the automated Human IK system window on the right, and the Outliner window on the left showing a schematic, graphic representation of the skeletal hierarchy. 


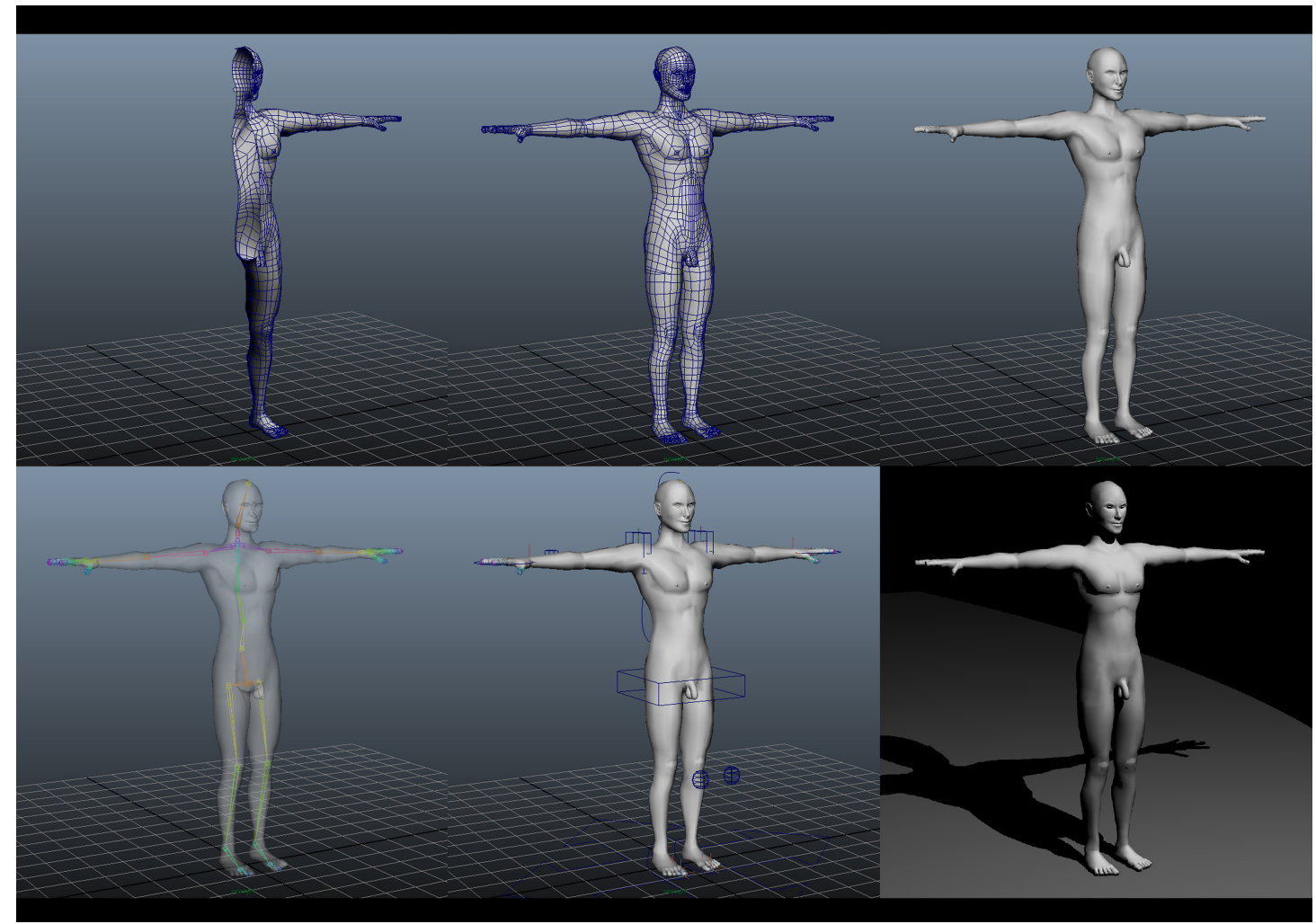

Figure 19. Modelling and creating skeletal rig.

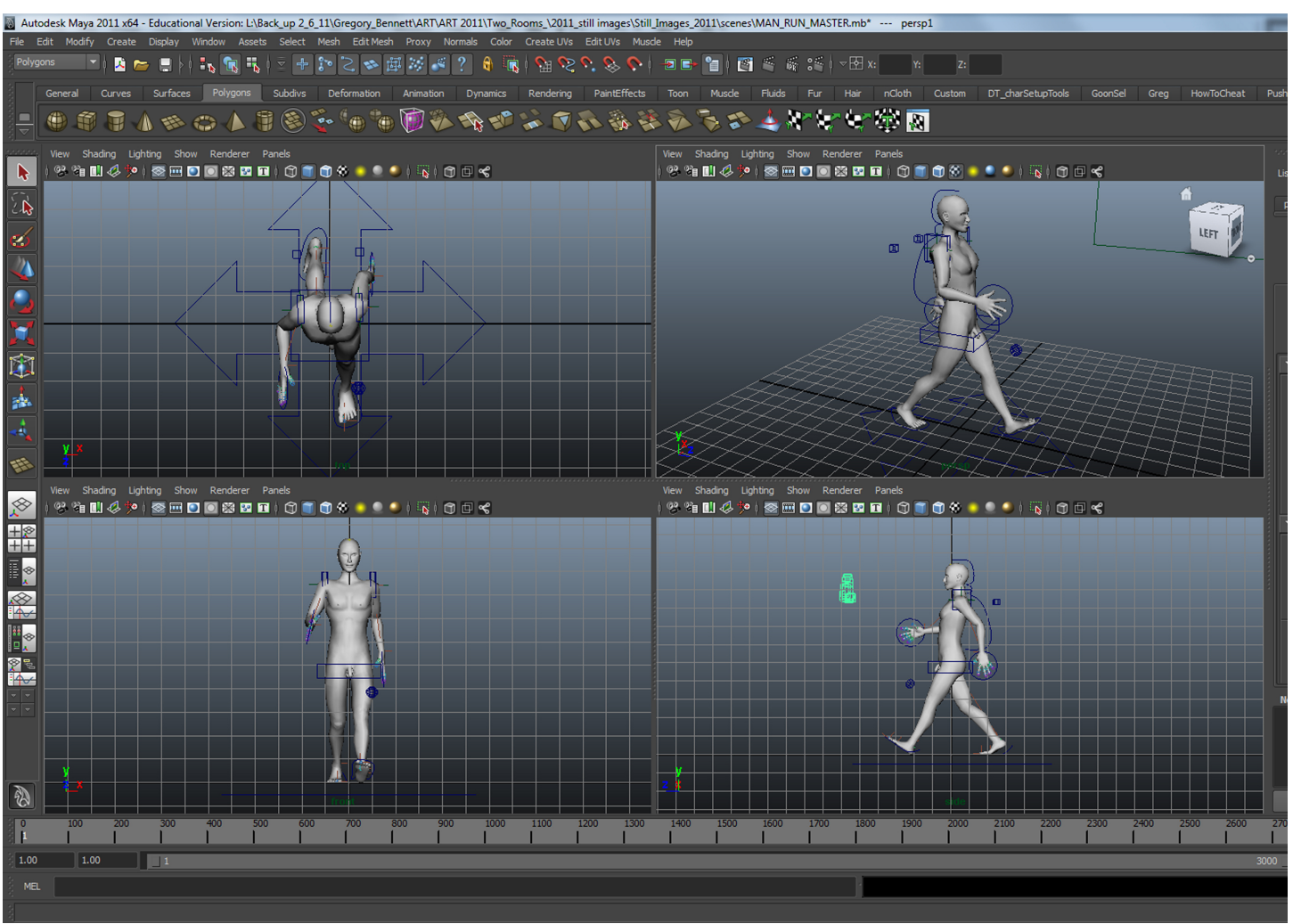

Figure 20. Creating a basic walk cycle using animation controls. 


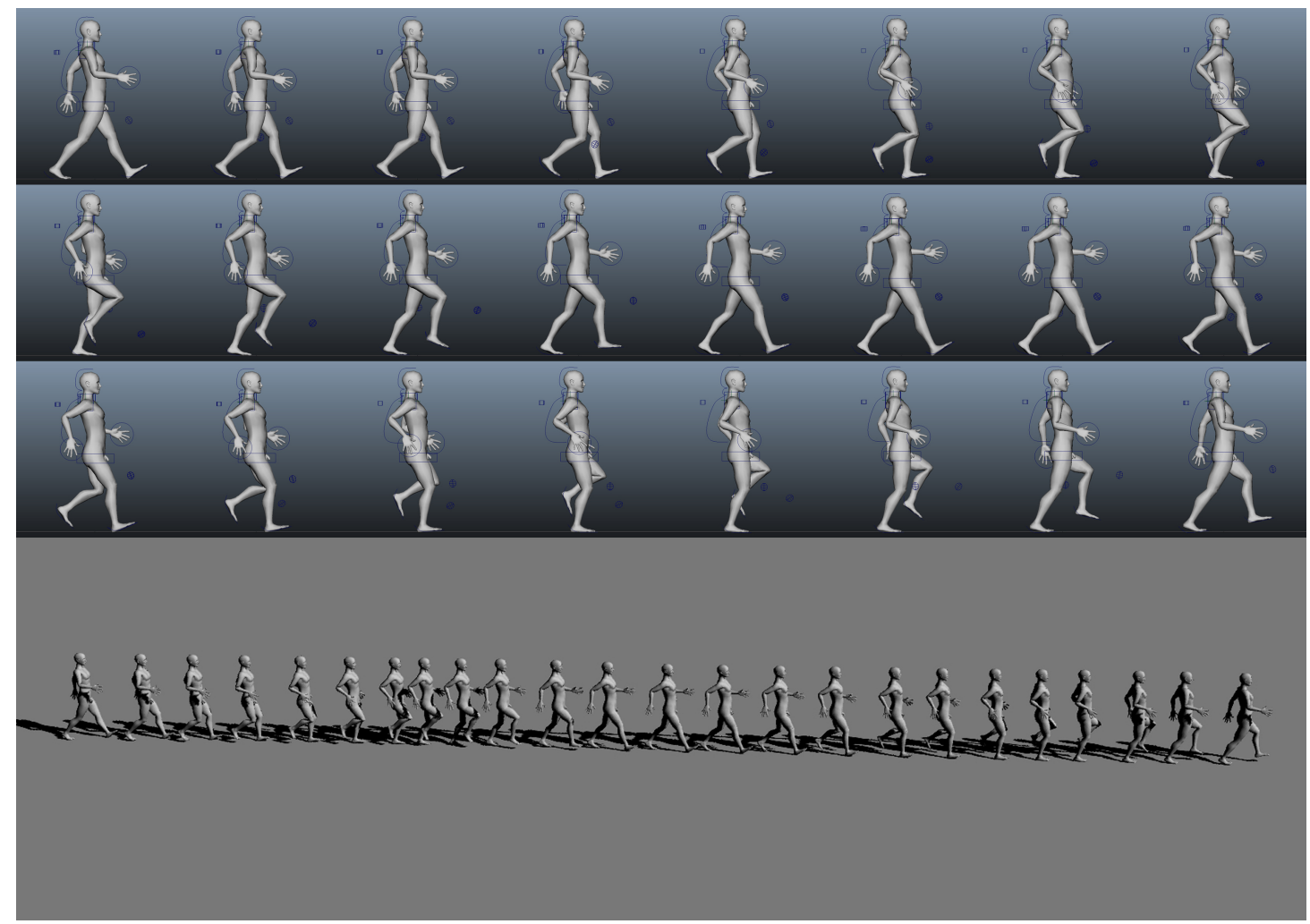

Figure 21. 24 different poses are created to animate a walk cycle.

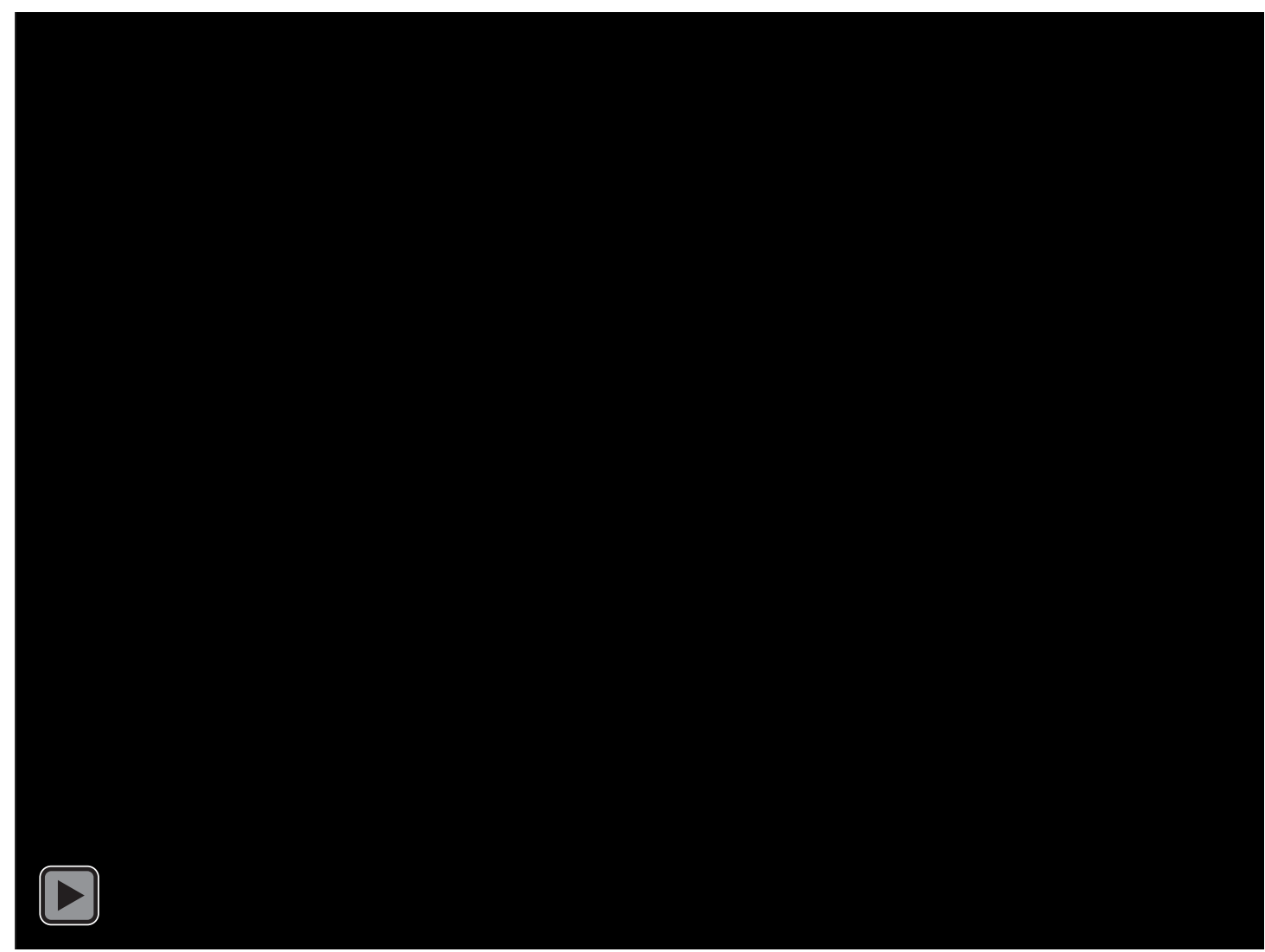

Figure 22. Modelling, rigging and animating.

A basic 25-frame walk cycle was then created using key-frames. The key-frame curves are then selected and set to loop automatically and infinitely, and saved as an 
animation clip. Engagement with the user-interface involves using the Viewer window to manipulate the $3 \mathrm{D}$ virtual representation of the figure interactively in order to create the incremental poses which collectively will form the walk cycle movement. It also requires developing knowledge of the Graph Editor, which shows a graphical representation of the animation data as animation curves. 3D animation automates part of the animation process by extrapolating the movements in between the manually set keyframes, labour which is undertaken by 'in-betweeners' in the $2 D$ drawn animation pipeline. The animation keyframes and curves can also be flexibly adjusted and manipulated in the Graph Editor as expertise is gained with this tool.

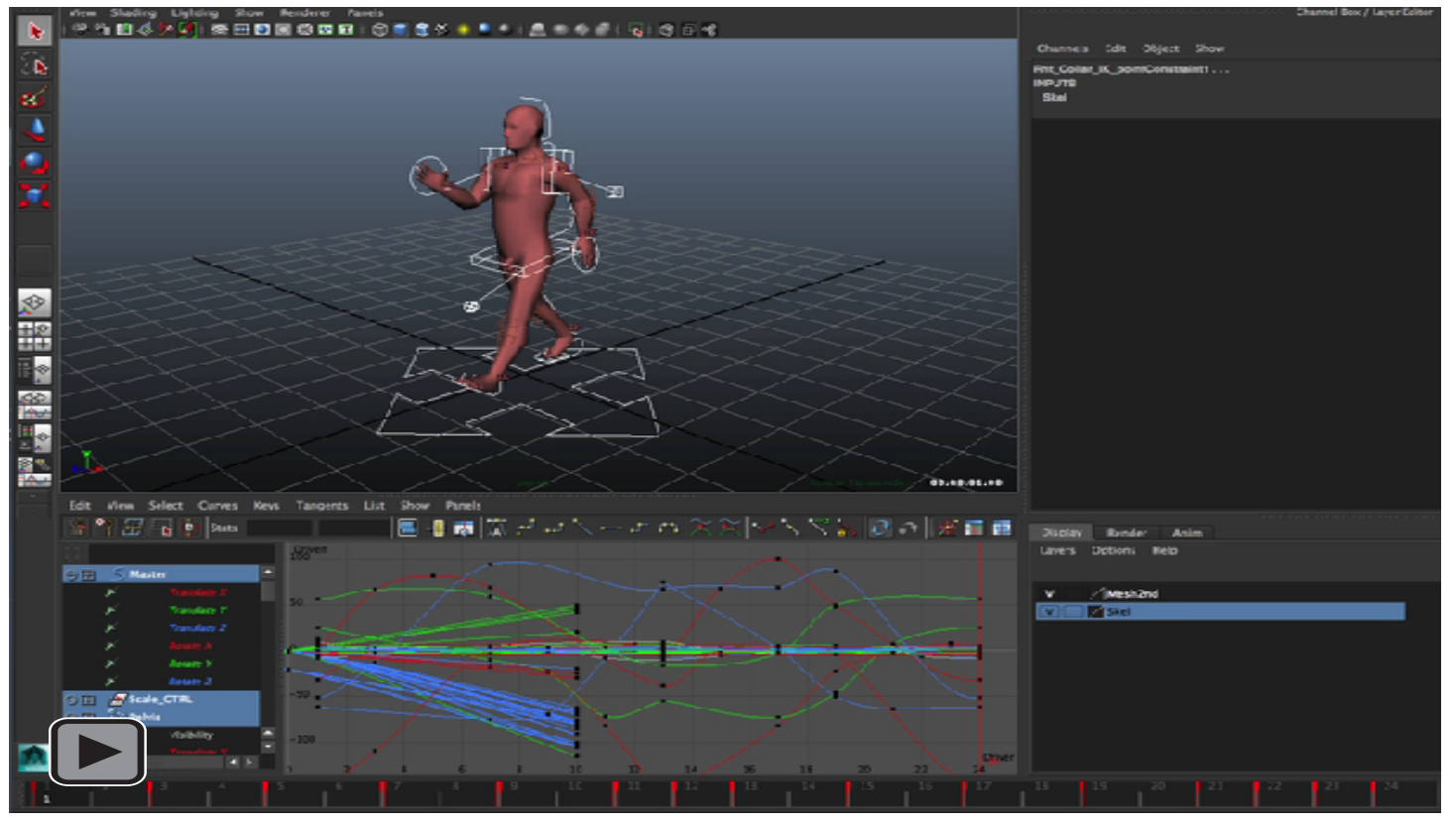

Figure 23. 24-Frame Animated walk cycle - Maya interface with the Viewer showing the animated figure in motion, the Graph Editor below and the Timeline at the bottom with the keyframes indicated by the red markers.

\section{The database as tool}

At this stage, the work immediately has status as a modular unit, which can be flexibly accessed, duplicated and modified. The efficiency around its use and re-useability supports a highly malleable explorative approach to creation where units of action can be variably organised and reorganised in virtual 3D space. Meaning can be created and recreated through a process of juxtaposition akin to of both the operations of cinematic montage and sculptural bricolage.

As well as walk and run cycles, other kinds of looped units of action were created with the figure, using the malleability of the skeletal rig to extend the movement vocabulary of the body beyond the naturalistic. At this stage a database is built up of a range of reusable and adjustable looped moving figures: all possible elements with which to select and build a range of sequences.

A key reference for me here is the elaborate geometric 'choreography' of 1930's Hollywood musical director Busby Berkeley, featuring armies of women whose individualism is radically reduced - as though all cast from the same mould. Here, as Lucy Fischer observes, 'their identities are completely consumed in the creation of an 
overall abstract design' (Fischer, 1989, p. 138). It is not so much choreography on display as 'kinetic designs' and 'mechanical decor' - 'elaborate preprogrammed machines for action' and 'repetitive movement' (Fischer, 1989, p. 140).

The association with the rhythms of mechanical movement seem always present when discussing Berkeley: Klaus Theweleit observes 'the legs and hands of the line-series are not saying anything, rather they are performing something: the modus operandi of cogs, mechanical links, belt transmissions...' (Theweleit,1992, p. 258). He adds that they are "ornaments of the technical performed"(Theweleit,1992, p. 258): machinic, subject, malleable, compulsively aping technical processes.

Here I substitute duplicated male figures for the de-individualised and multiplied female. Extending the possibilities of collective ornament and pattern generation practised by Berkeley, these digital figures are manipulated into 'impossible' pose and movement configurations, and then copied and pasted repeatedly in circular formations, also allowing the figures' geometry to interpenetrate. Sequences are constructed in a modular fashion - adding a figure in an infinite looped movement cycle, duplicating and arranging it in various configurations.

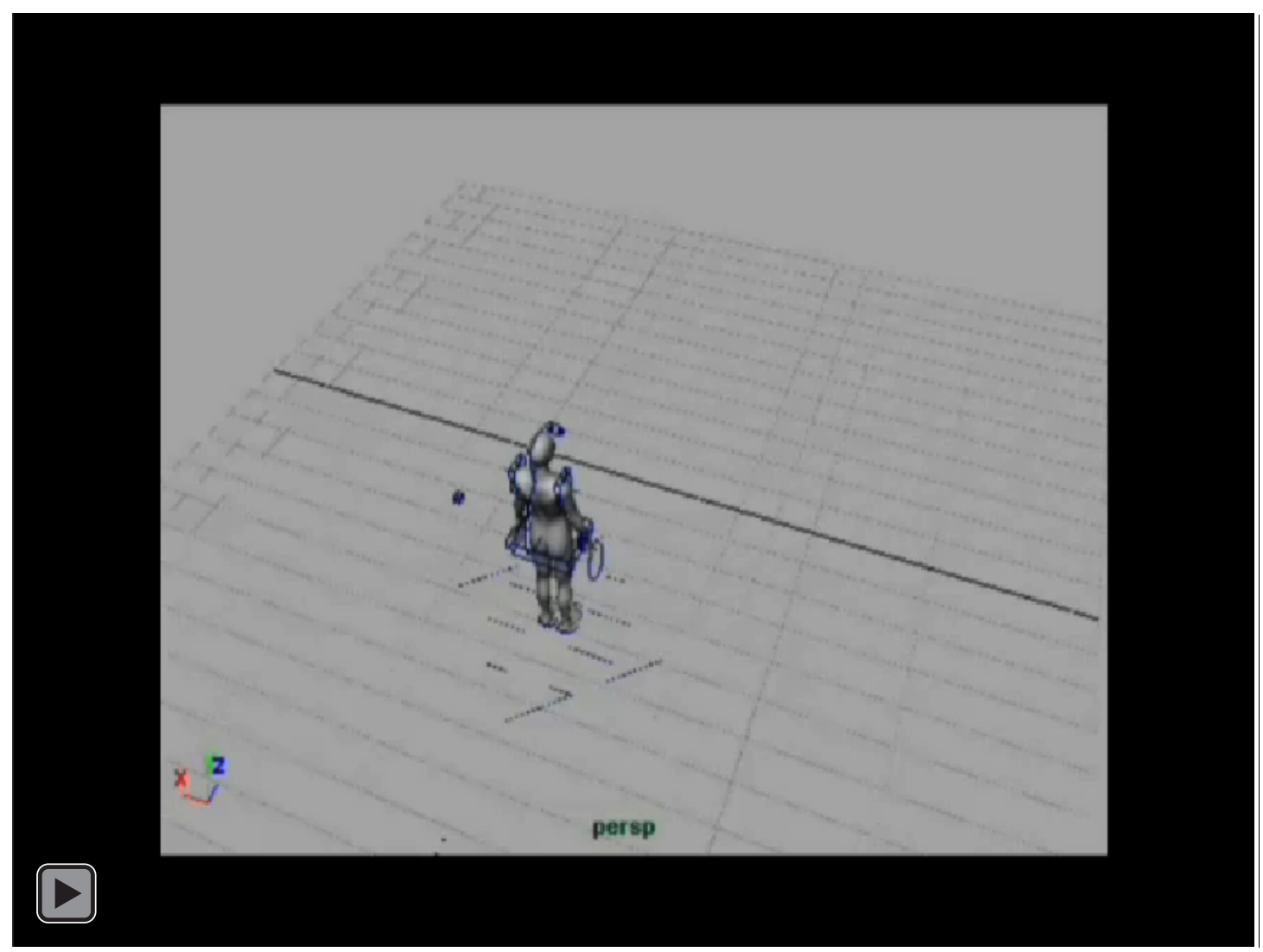

Figure 24. Looped figure animations are duplicated, offsetting their position in a circular construction. Varying the number of figures and the space between each of them, and having the freedom to allow inter-penetration of the skin mesh saw a metamorphic transformation of form. 


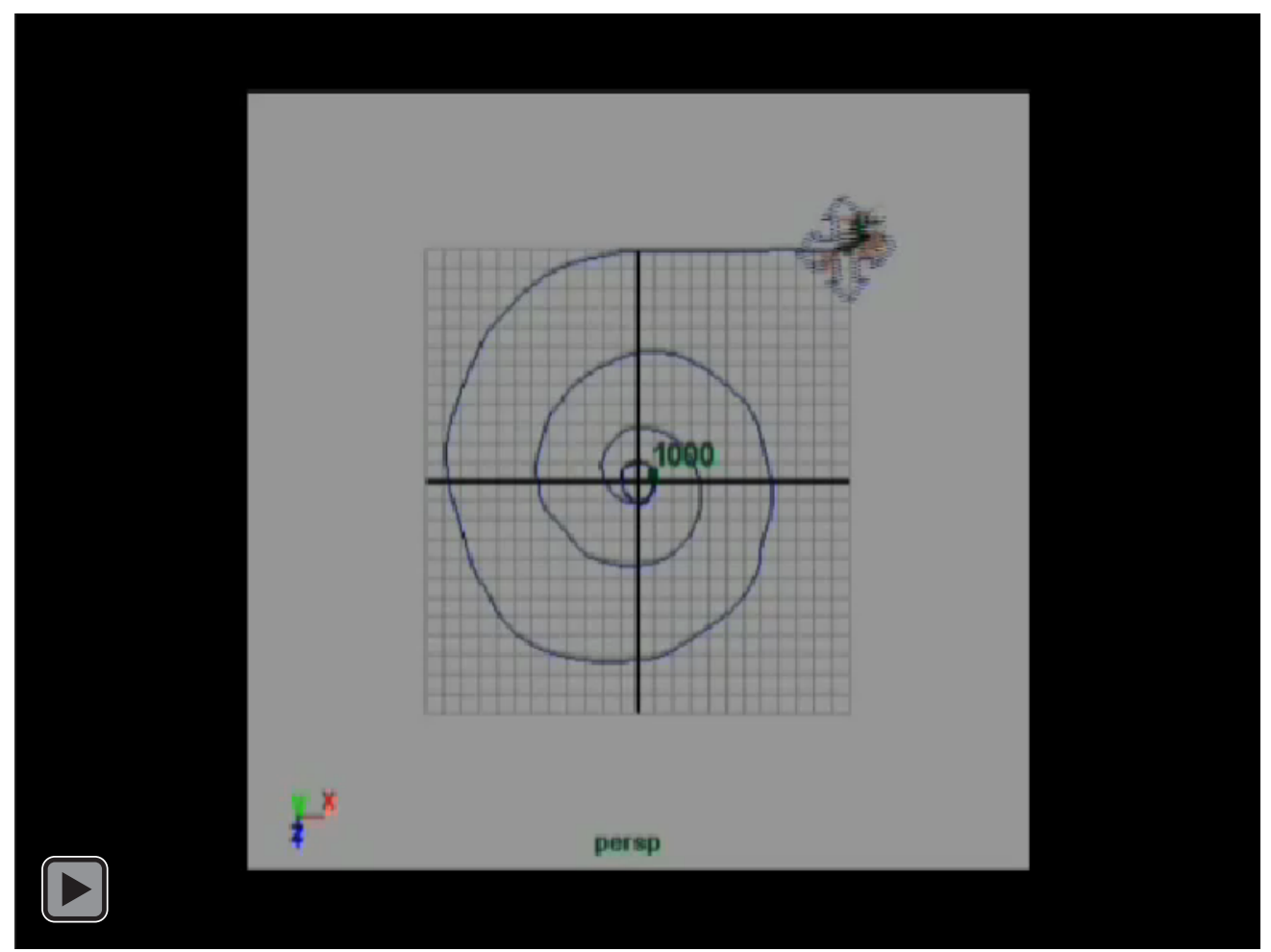

Figure 25. Ambulatory figures were assigned to motion paths, which takes the looped walk cycle and automates its trajectory along a defined curve, creating a further modular unit which could be re-positioned, duplicated, and altered flexibly to create a range of variable sequences.

The animated figure is employed as a building block in the creation of a series of works which assembles and reassembles the replicated figure into units of performed actions, loops and cycles, creating a series of patterns of movement vocabulary.

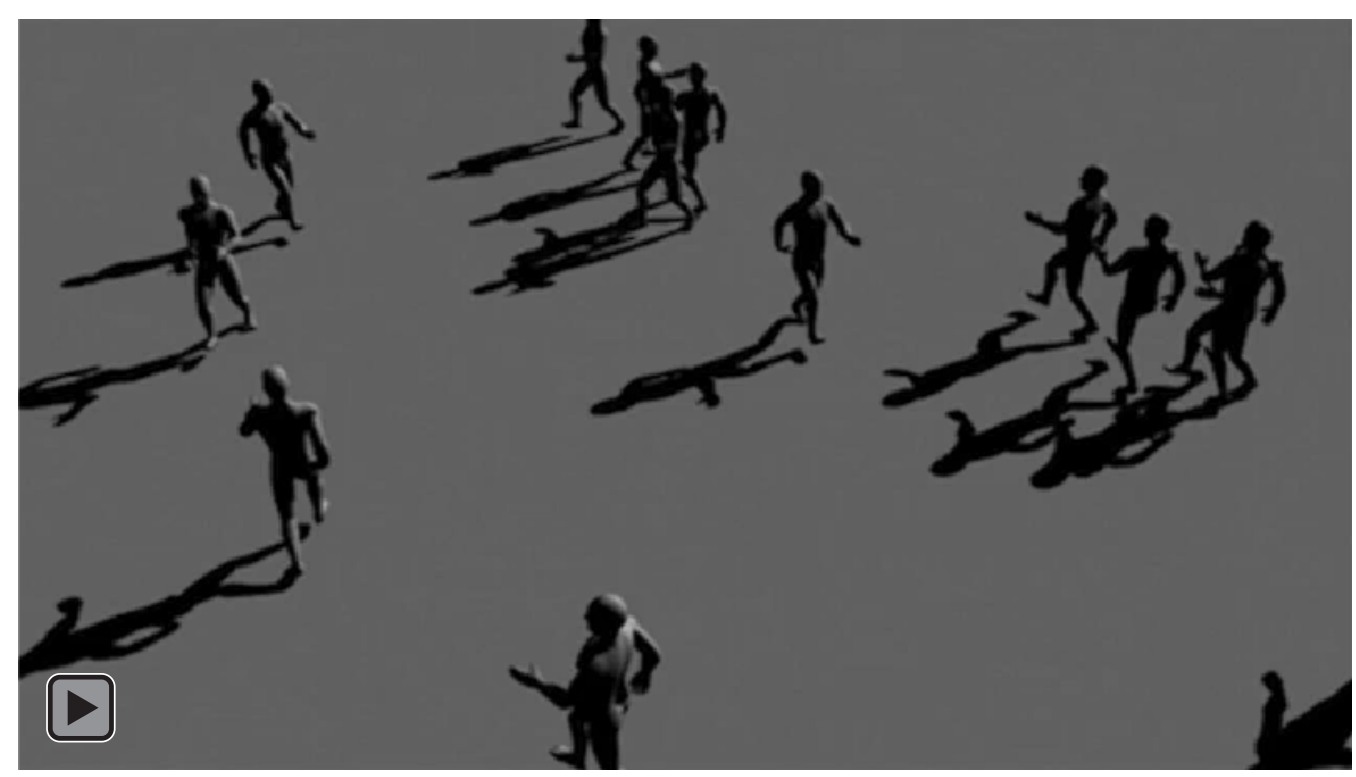

Figure 26. Animation tests of duplicated figure groups with a range of animated loops and paths.

These in turn are placed in environmental and/or architectural settings, which again are created and stored as modular elements that can be flexibly accessed, and combined and recombined. 


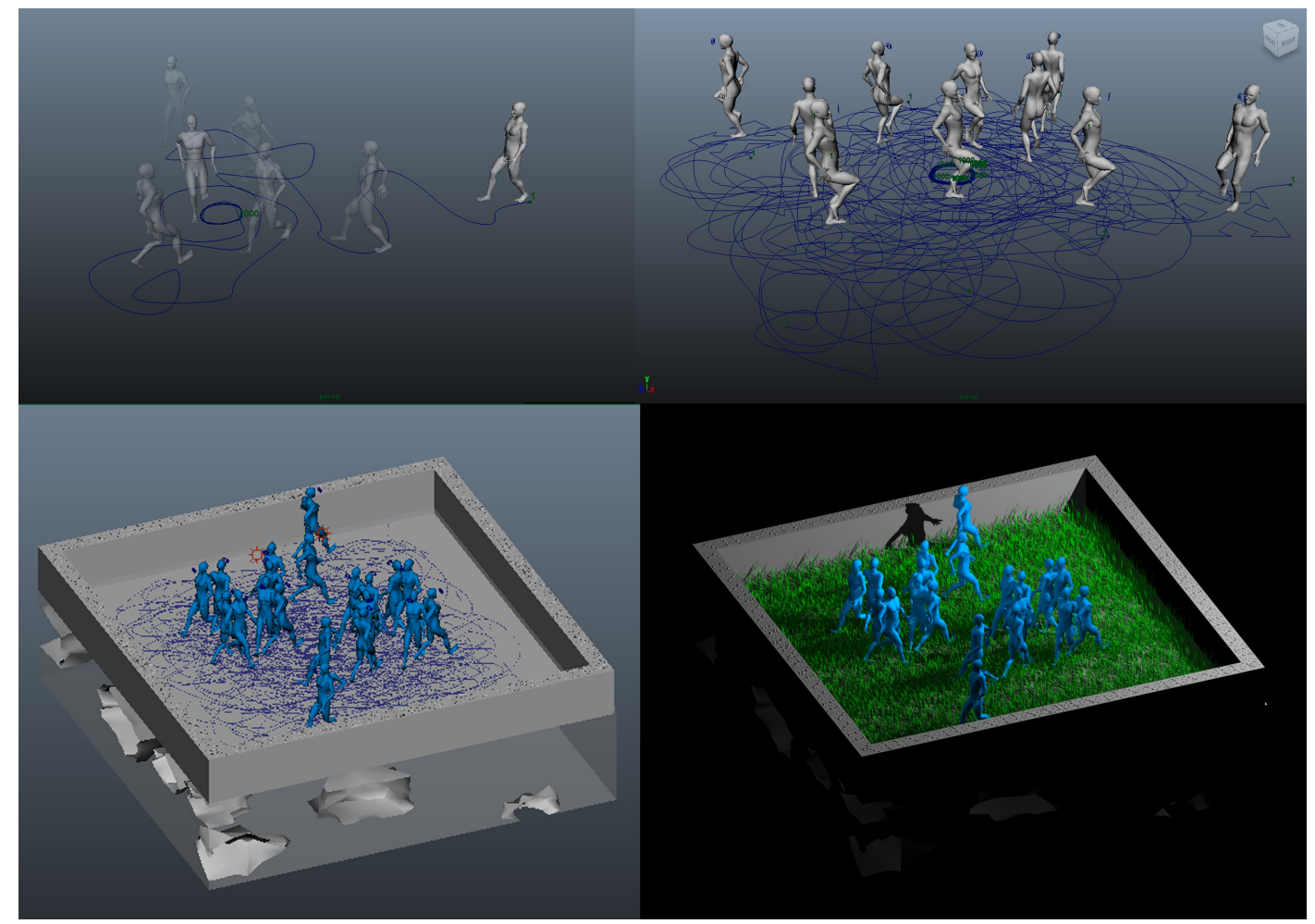

Figure 27. Looped animated figures are duplicated and assigned to motion paths. These are then placed in 3D environments.

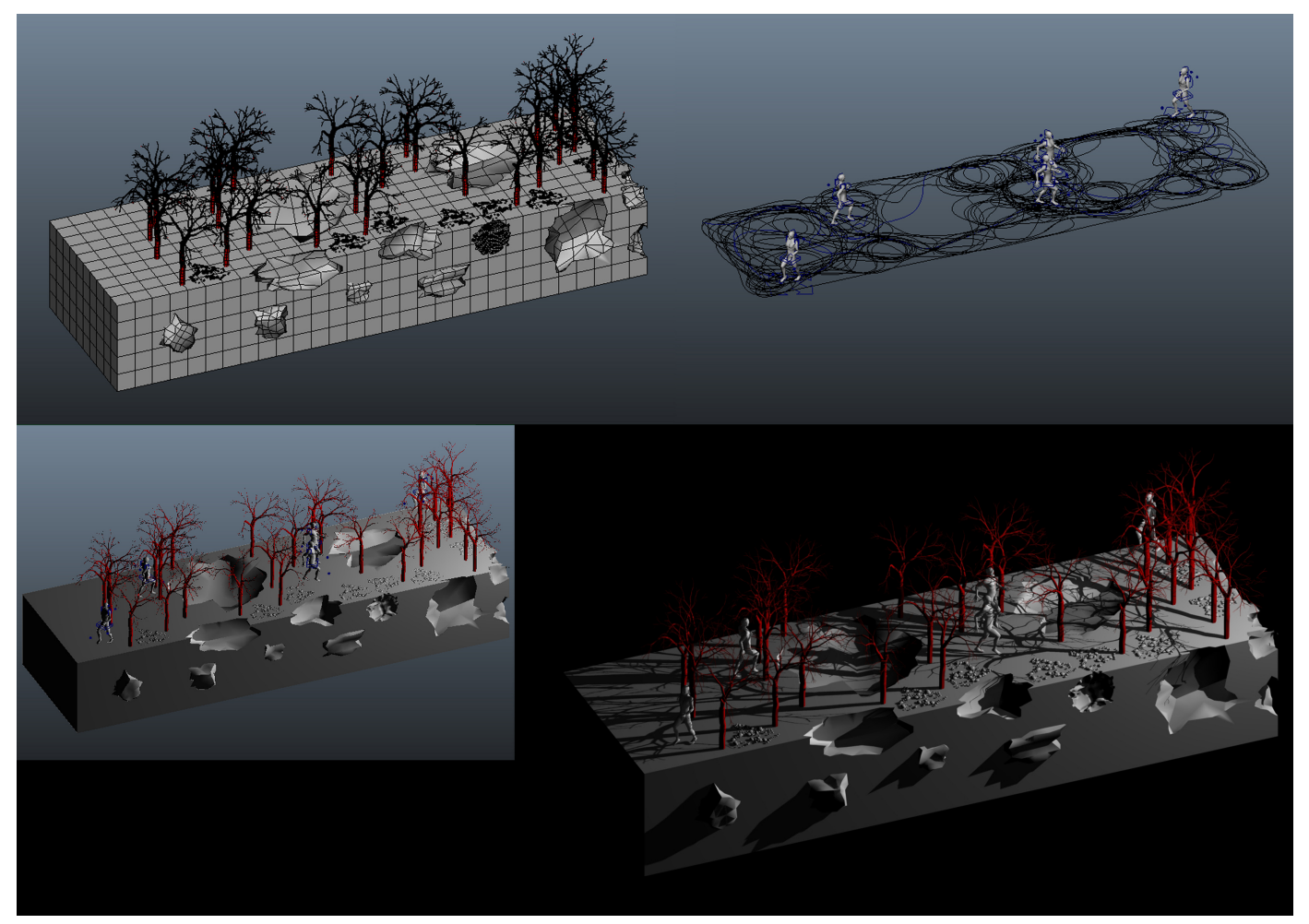

Figure 28. Looped animated figures - example 2 


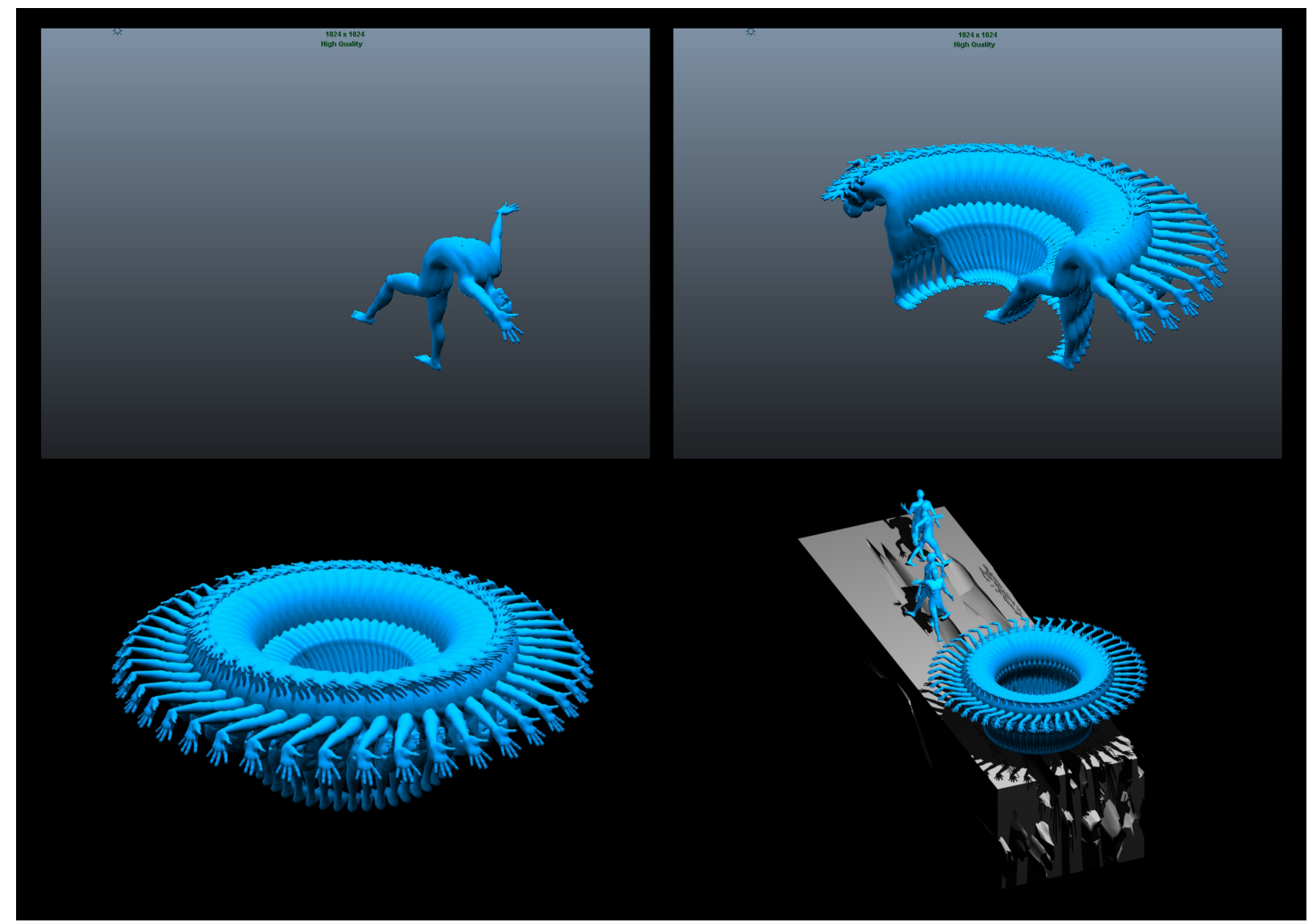

Figure 29. A database of 'already-activated elements' can then be drawn on to construct larger composite environments.

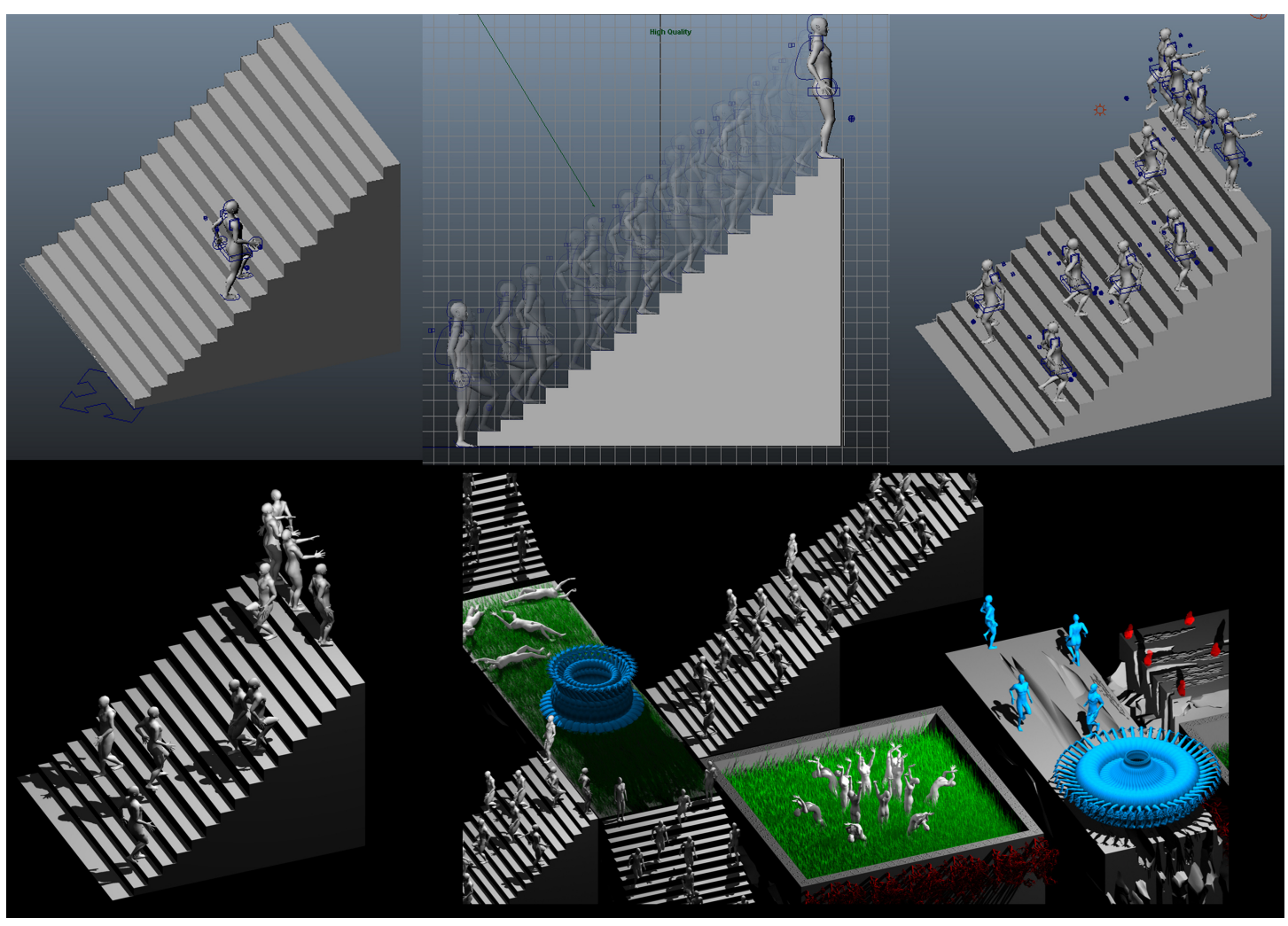

Figure 30. A database of 'already-activated elements' - example 2 


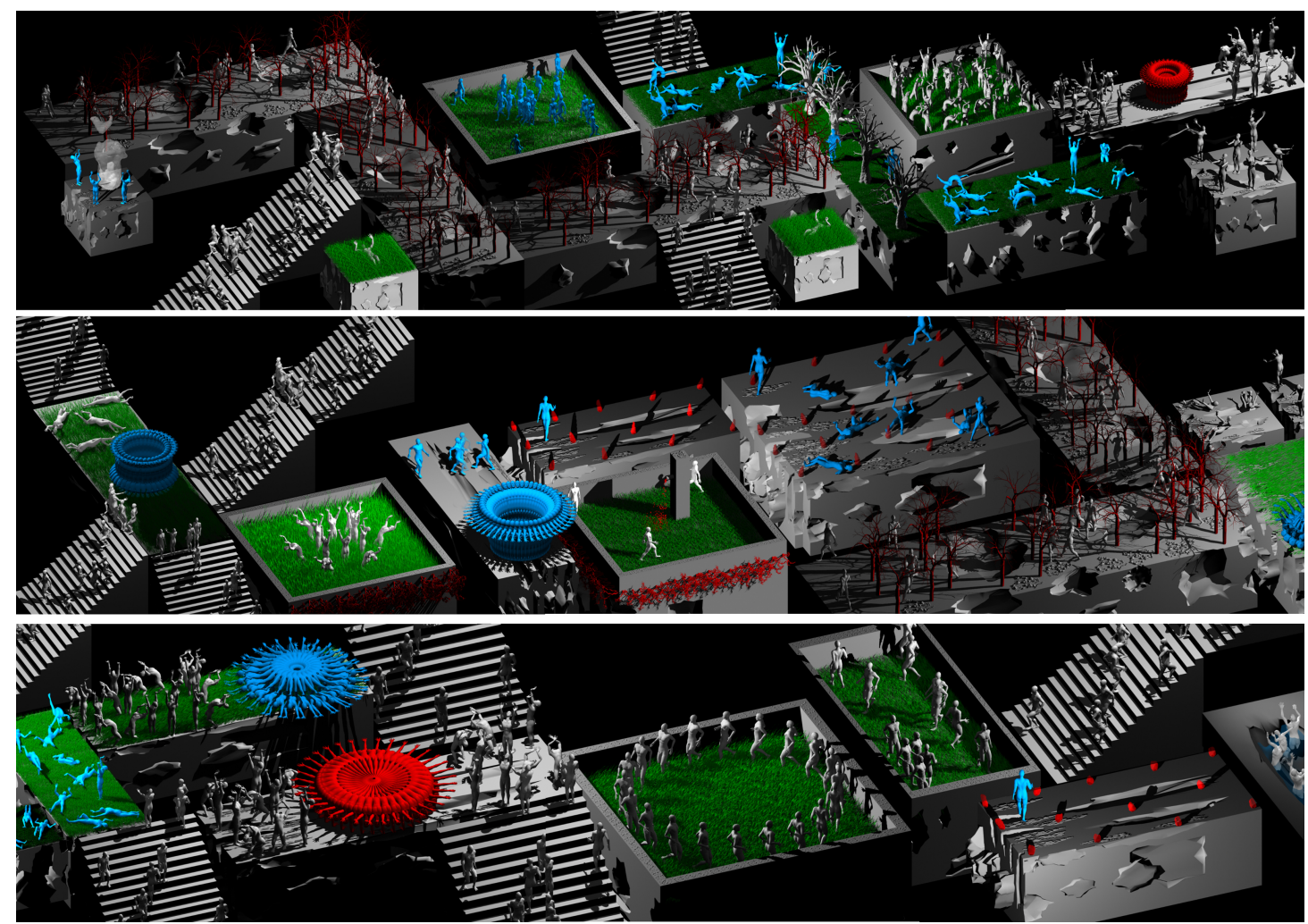

Figure 31. Elements from the 'database' are flexibly arranged and re-arranged to form a continuous virtual 'world'.
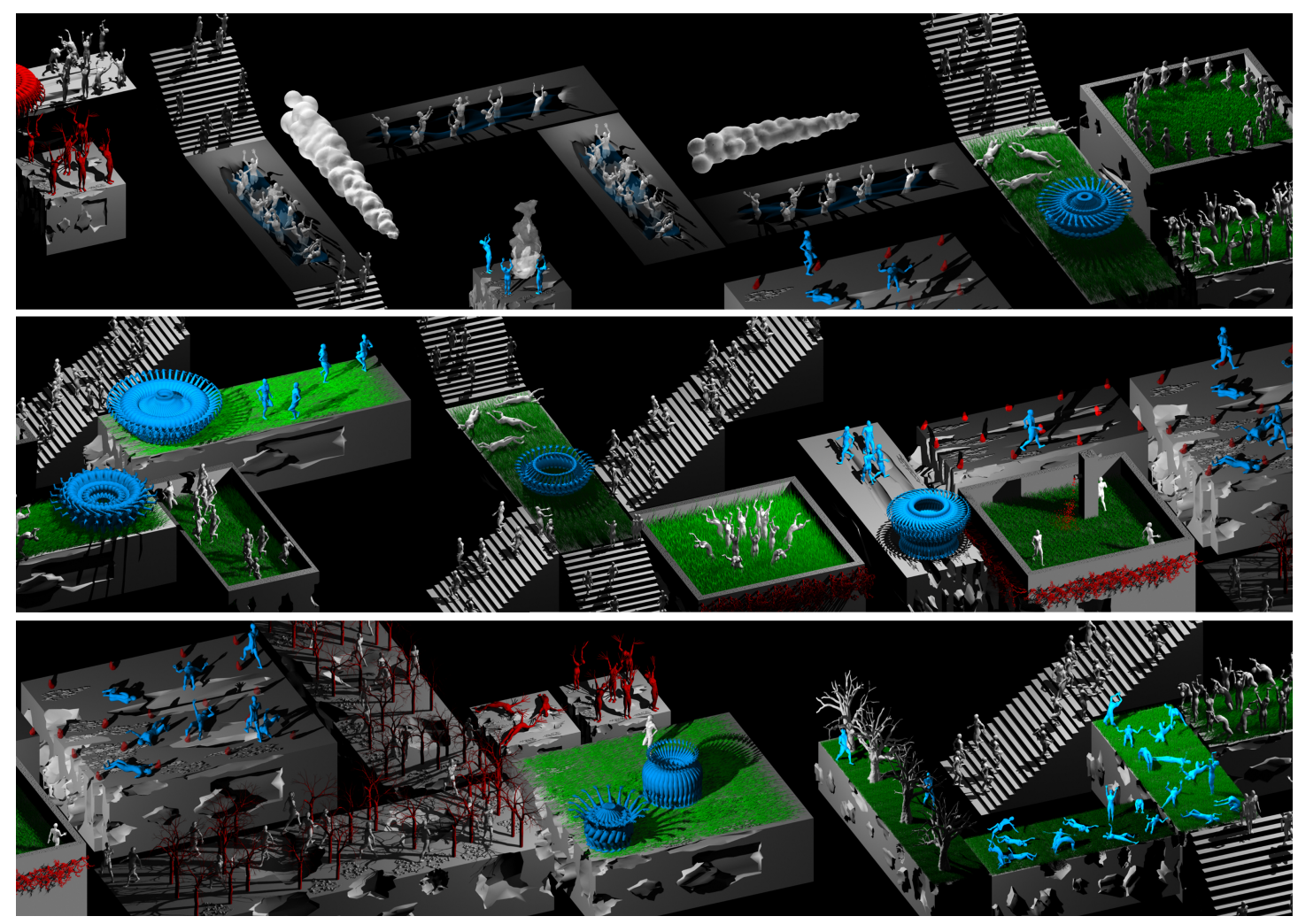

Figure 32. Elements from the 'database' - example 2 


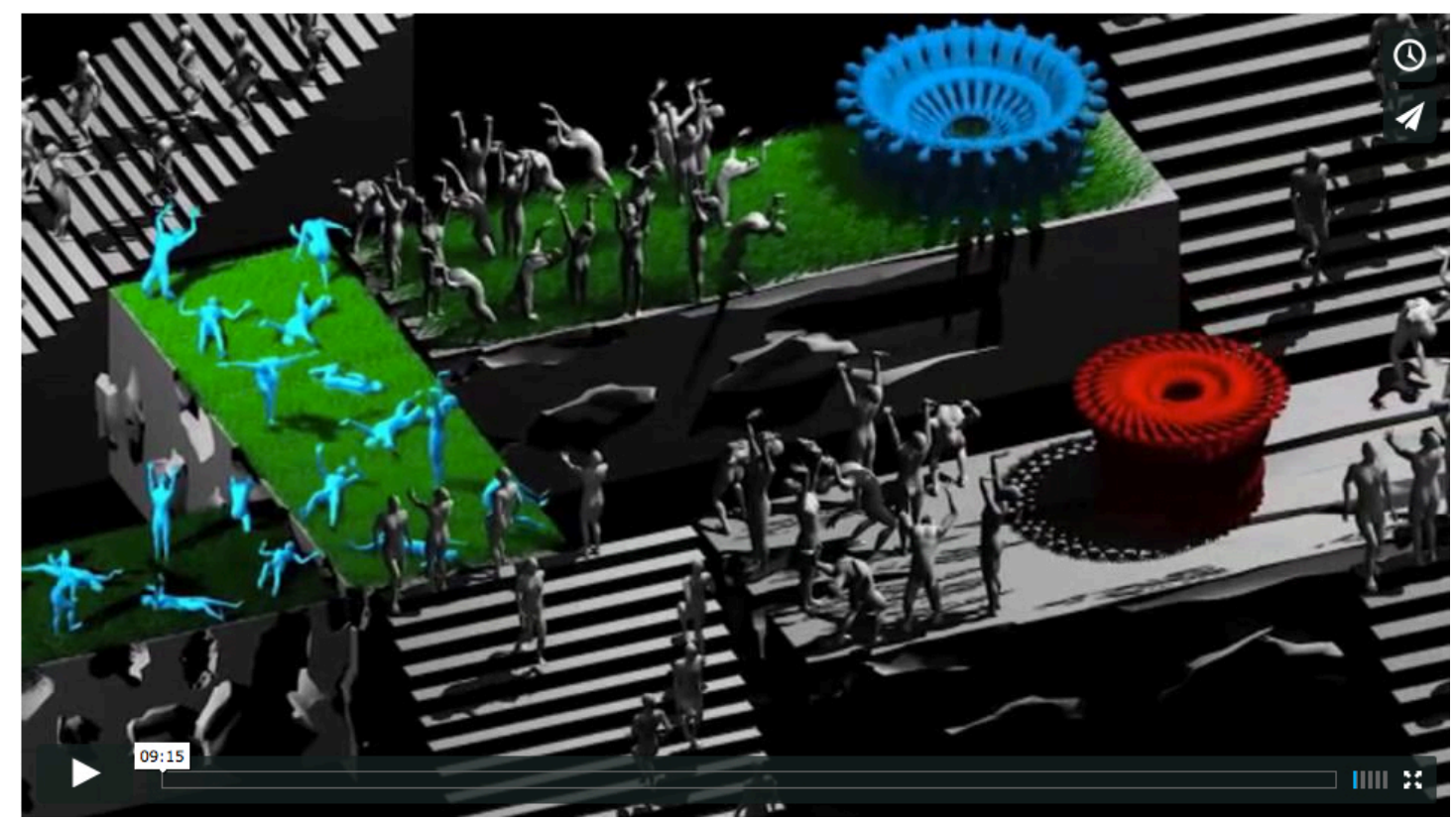

Figure 33. Utopia I (2011)

This process continues as a growing database is built as new works are generated from the combination and recombination of elements into more complex configurations.

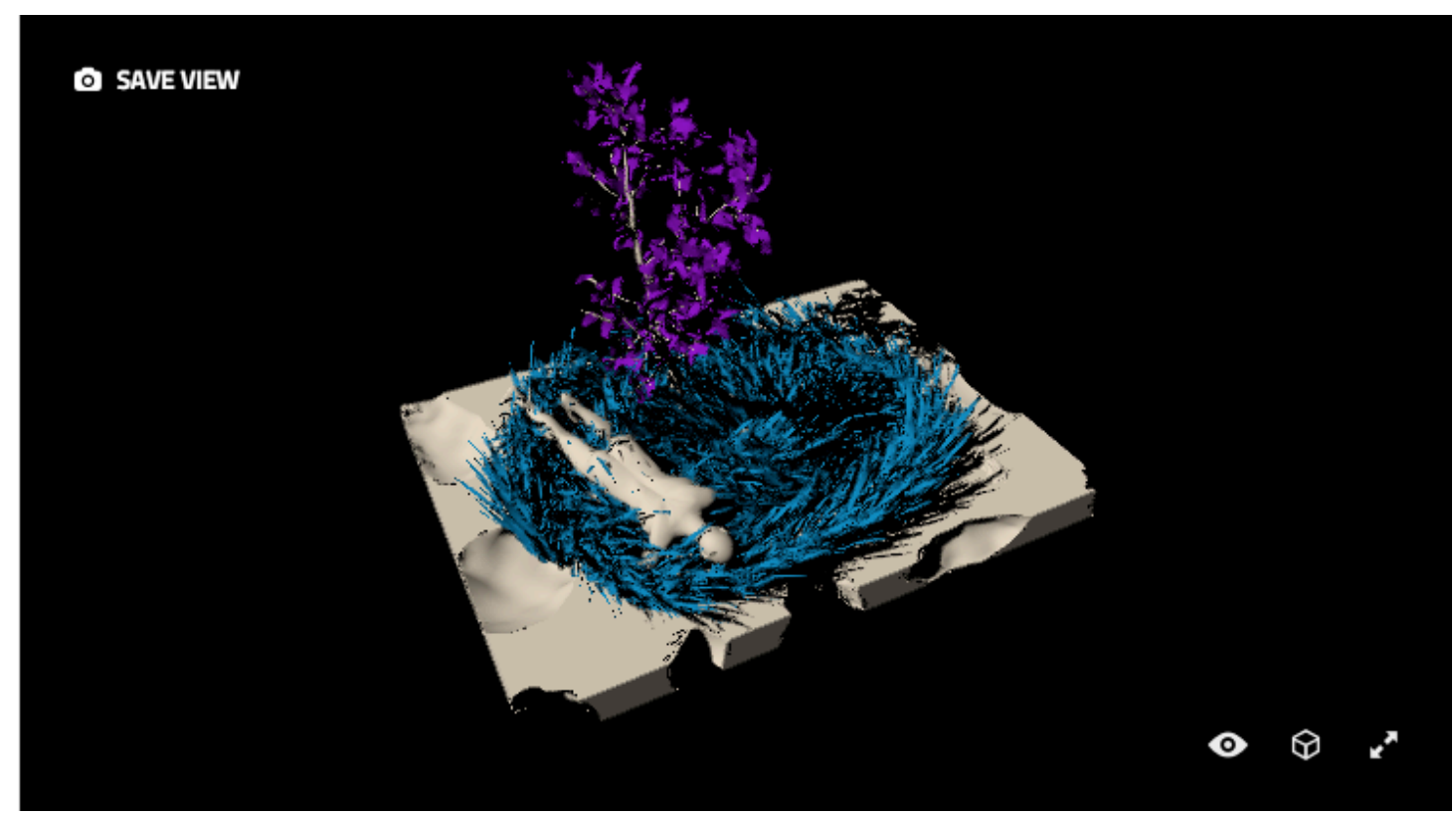

Figure 34. 3D model from Utopia IV (2013) 


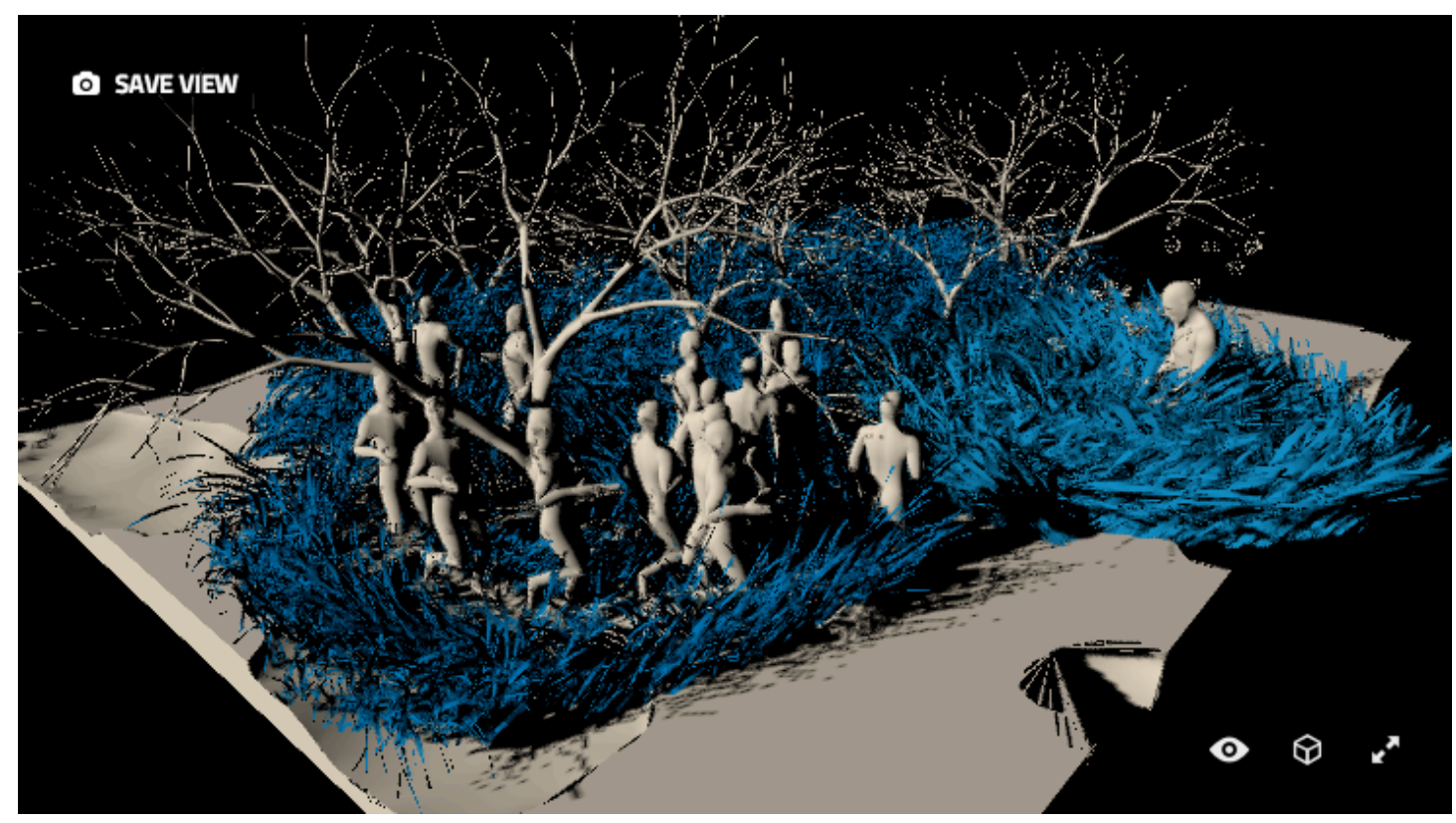

Figure 35. 3D model from Utopia IV (2013)

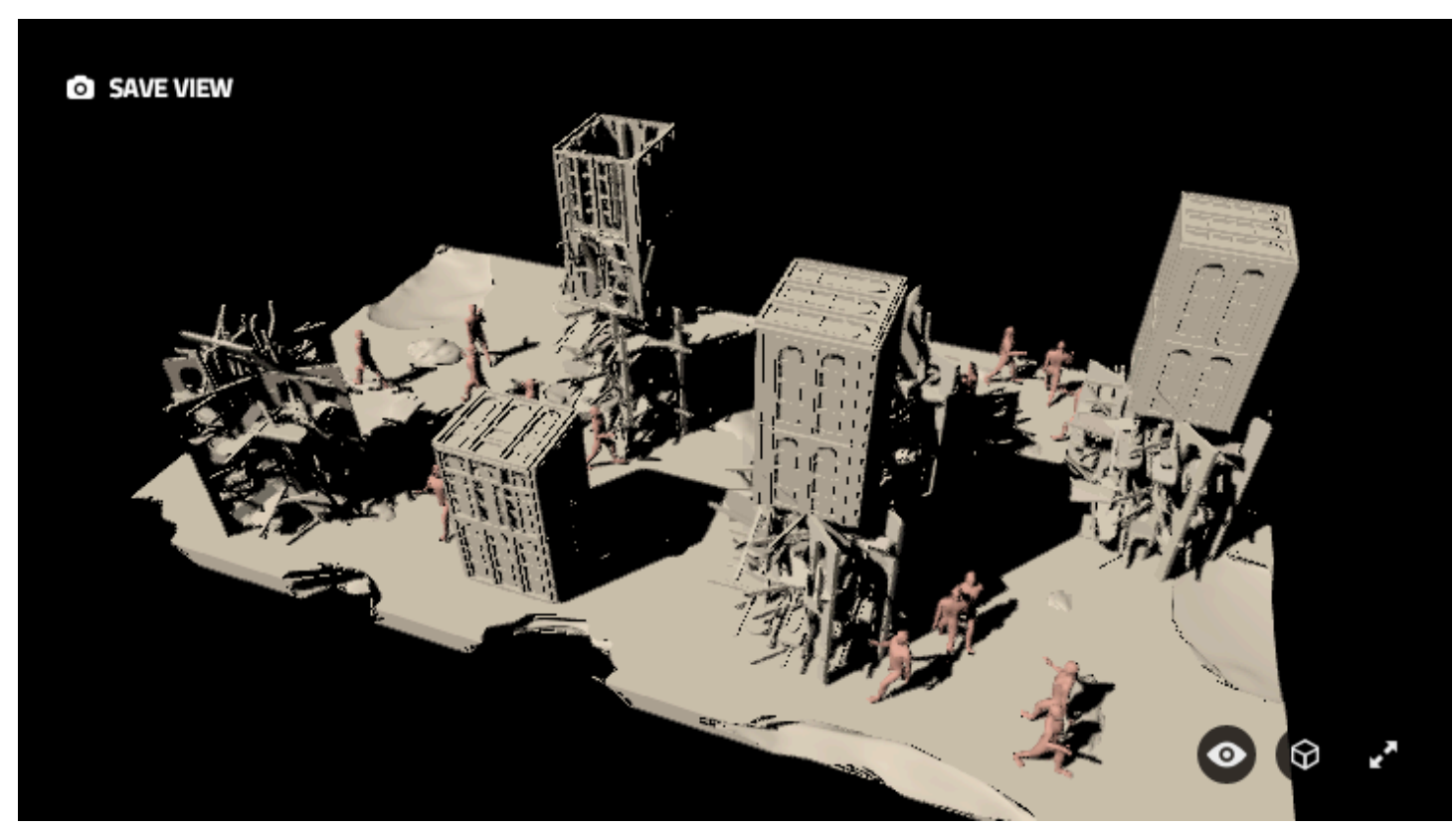

Figure 36. 3D model from Utopia IV (2013) 


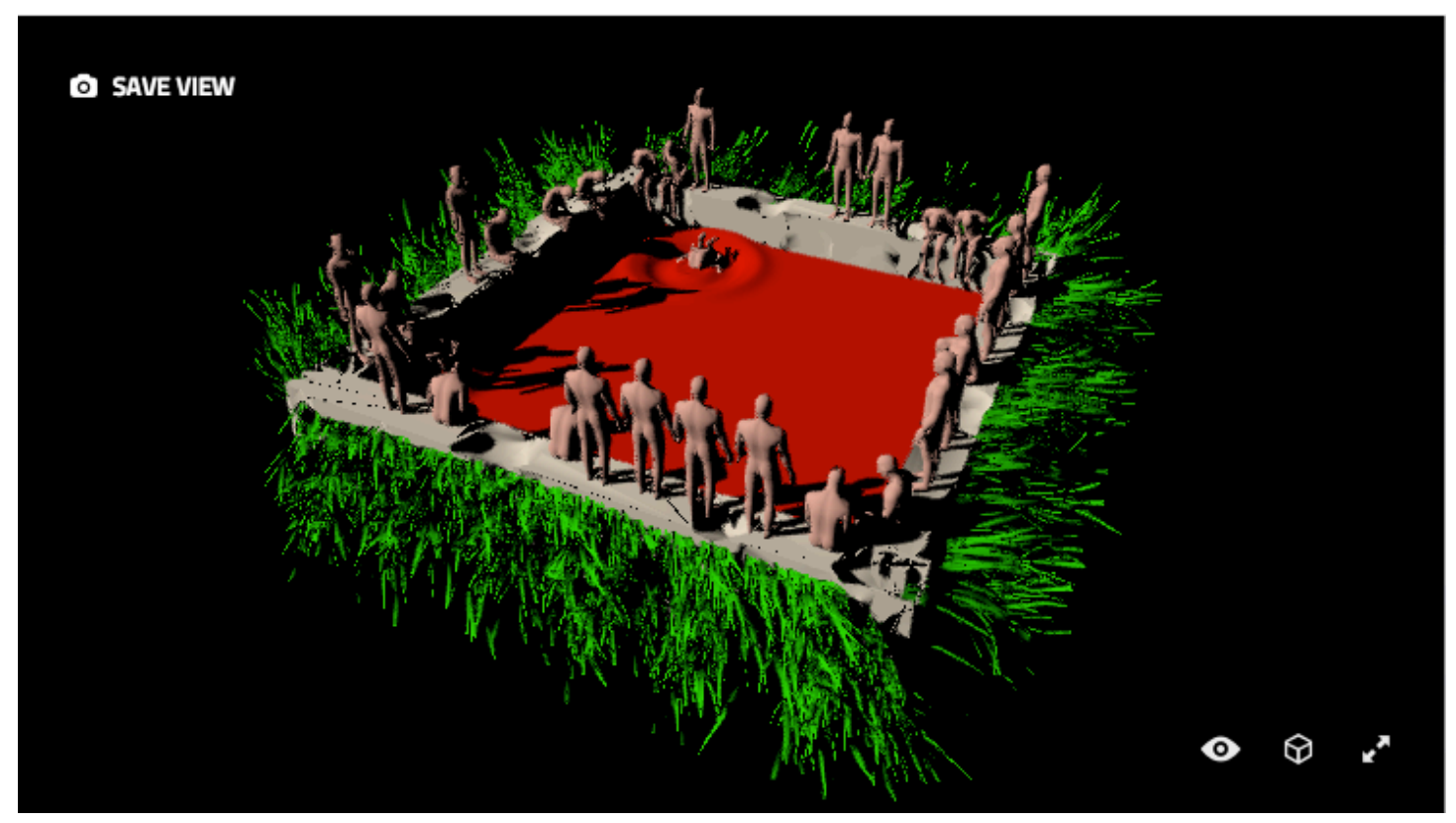

Figure 37. 3D model from Utopia IV (2013)

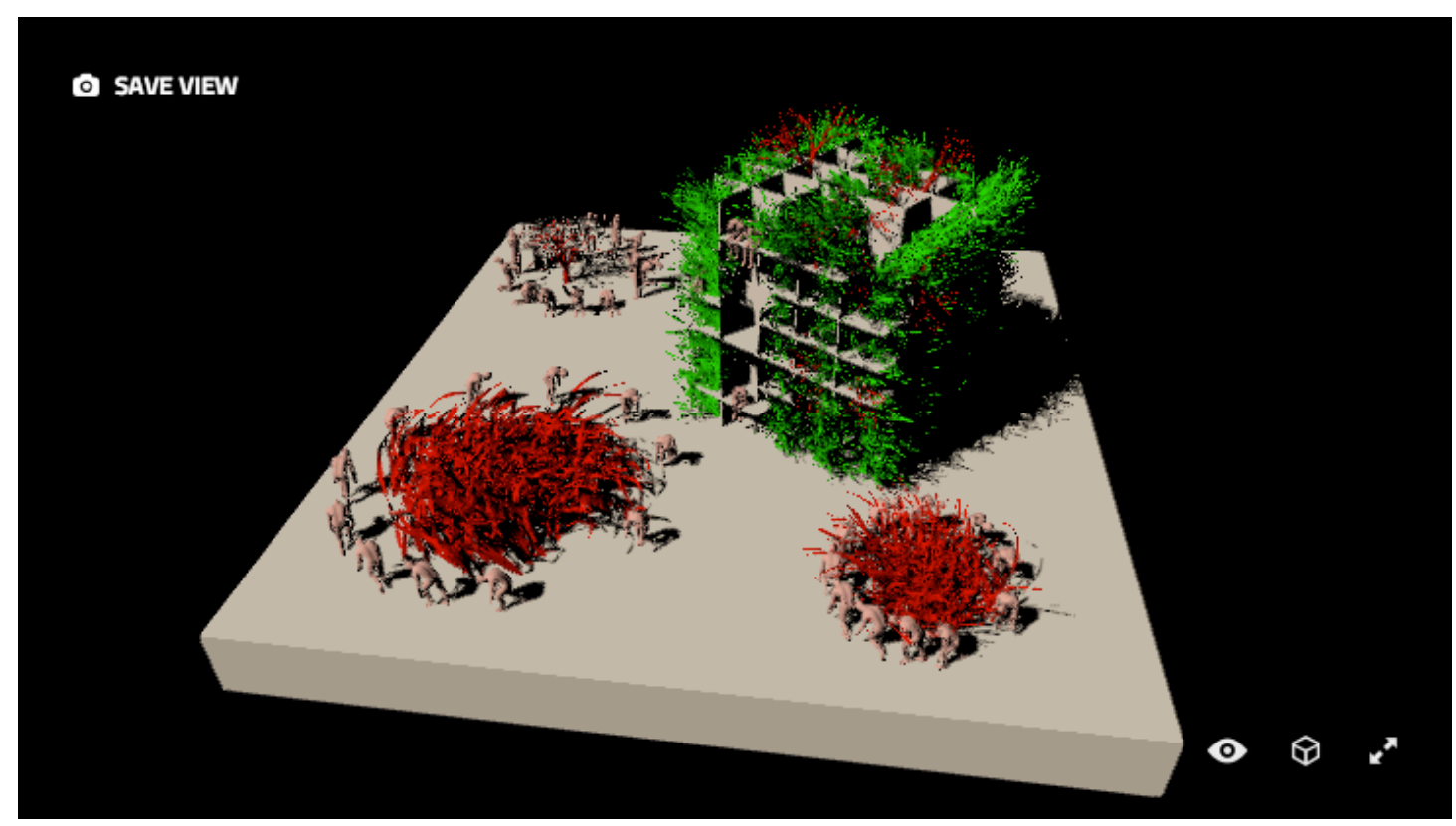

Figure 38. 3D model from Utopia IV (2013) 


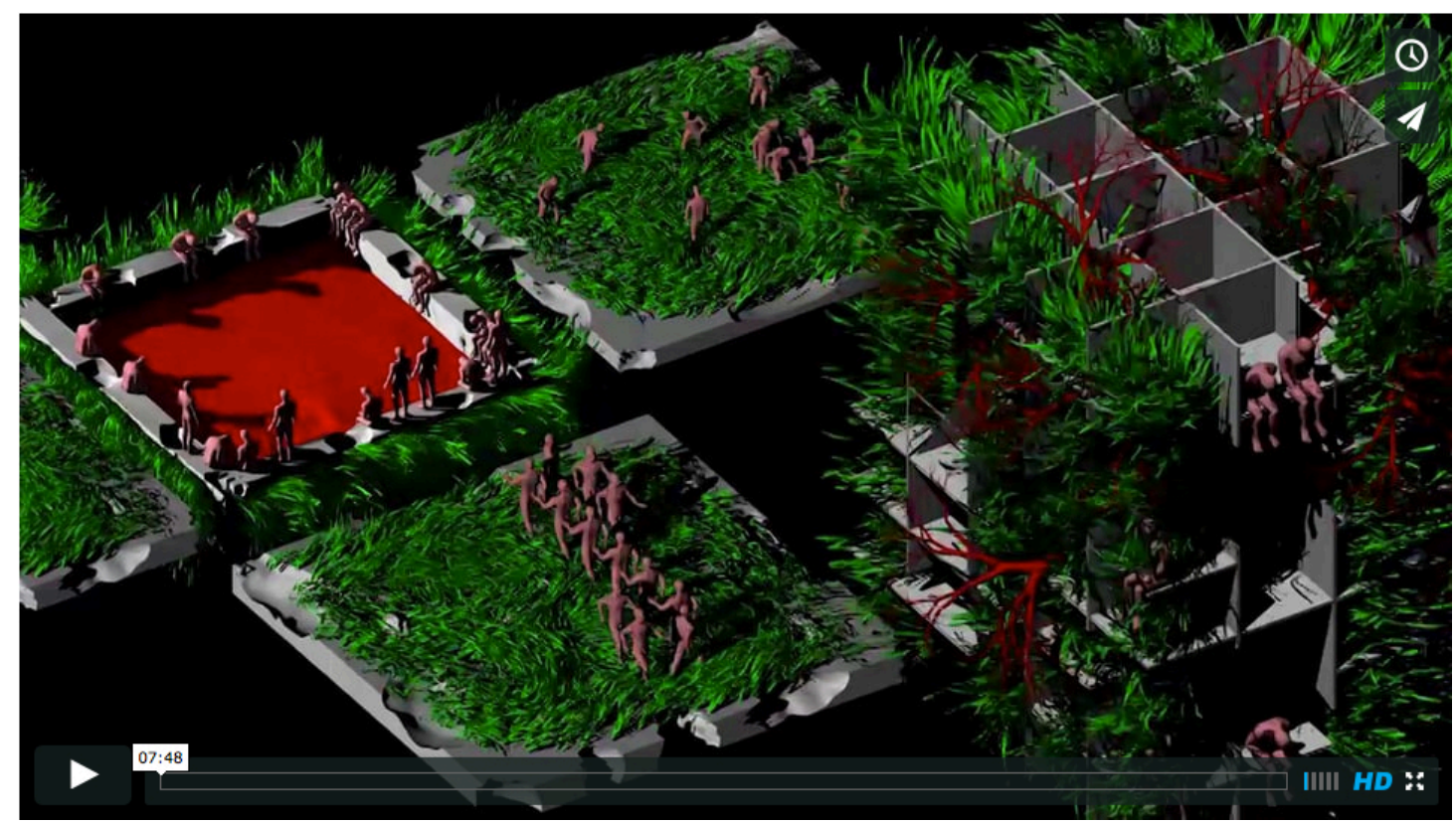

Figure 39. Utopia IV (2013)

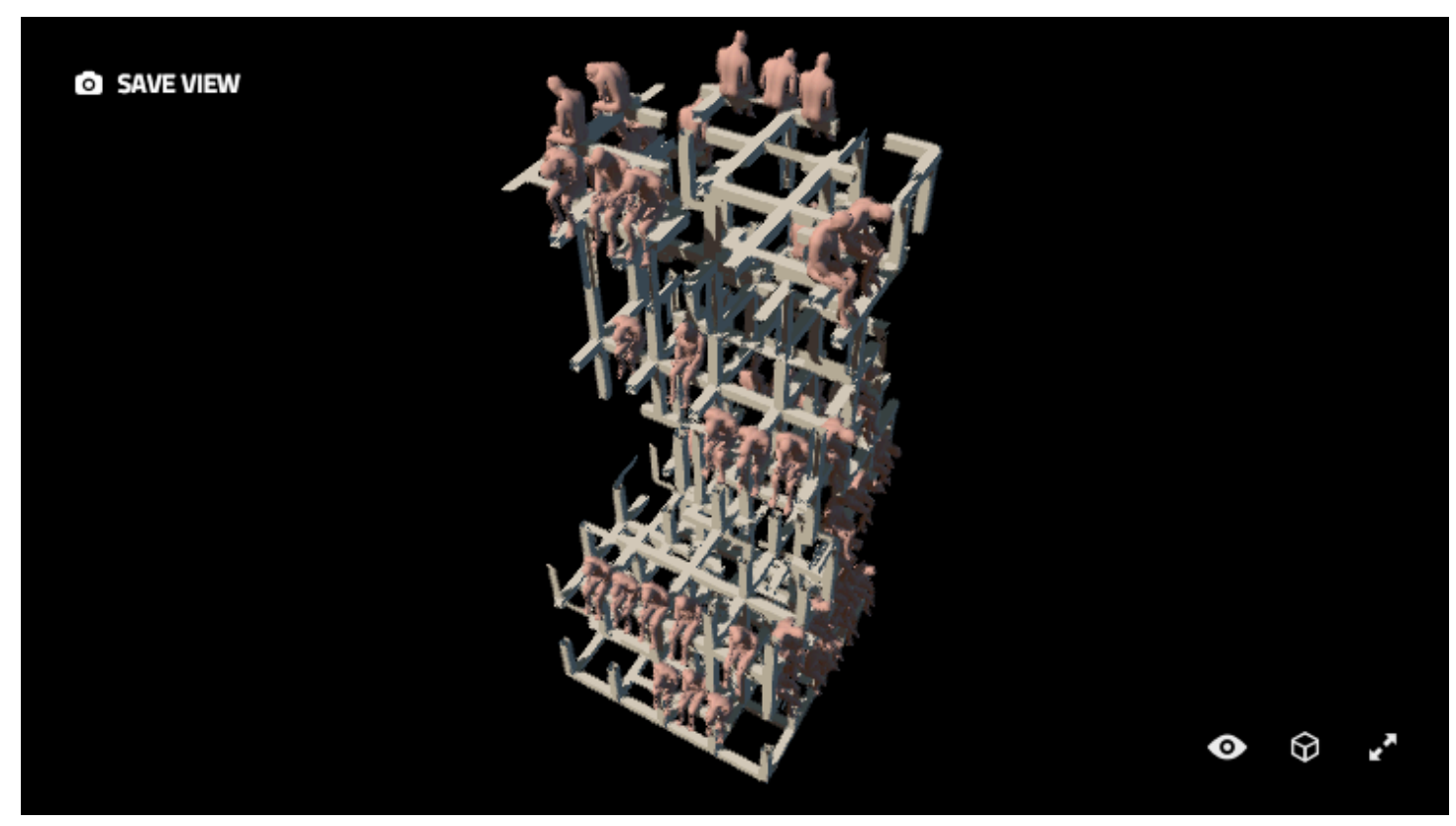

Figure 40. 3D model from Dromosphere I (2013) 


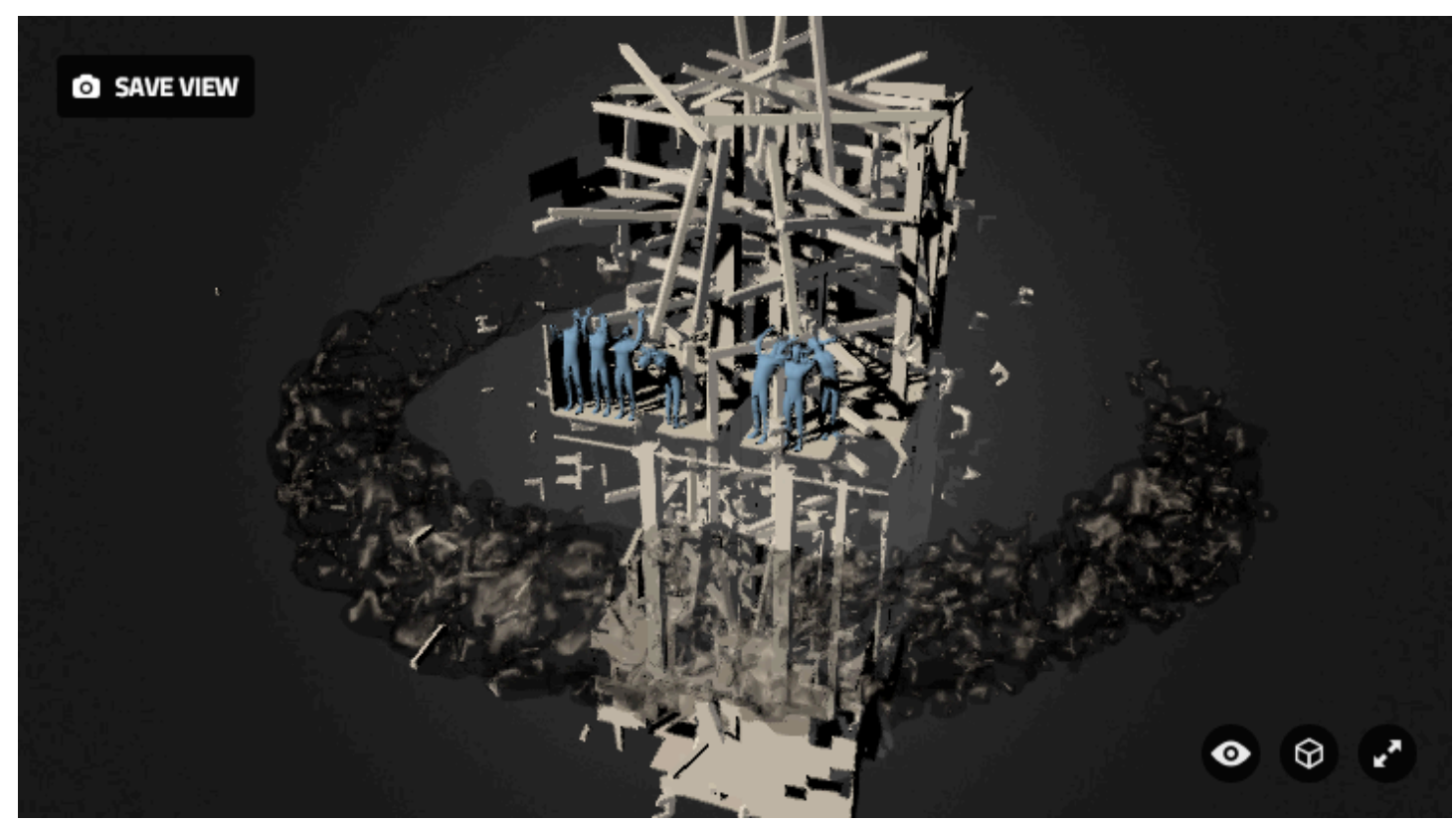

Figure 41. 3D model from Dromosphere I (2013)

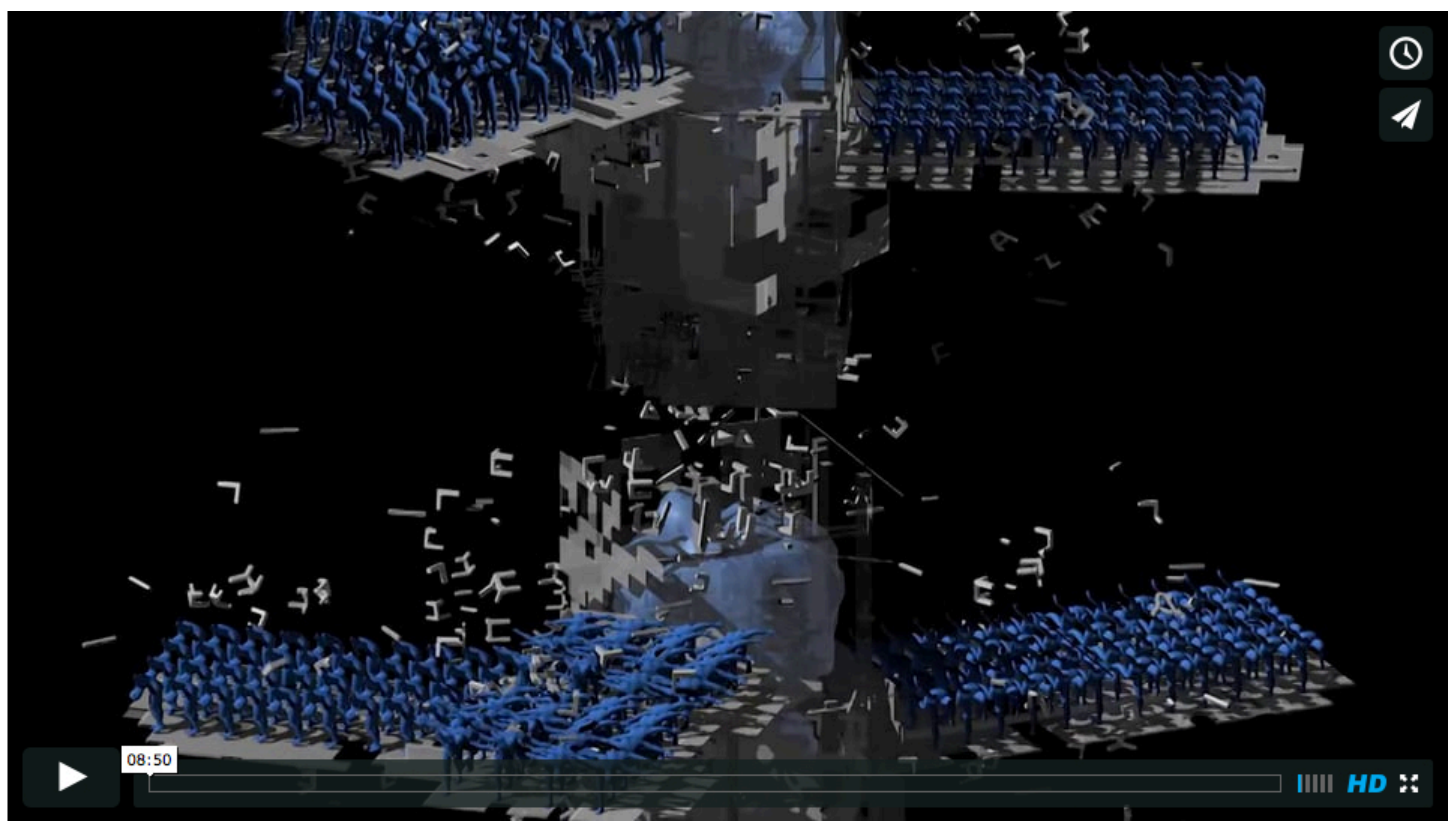

Figure 42. Dromosphere I (2013) 
D SAVEVIEW

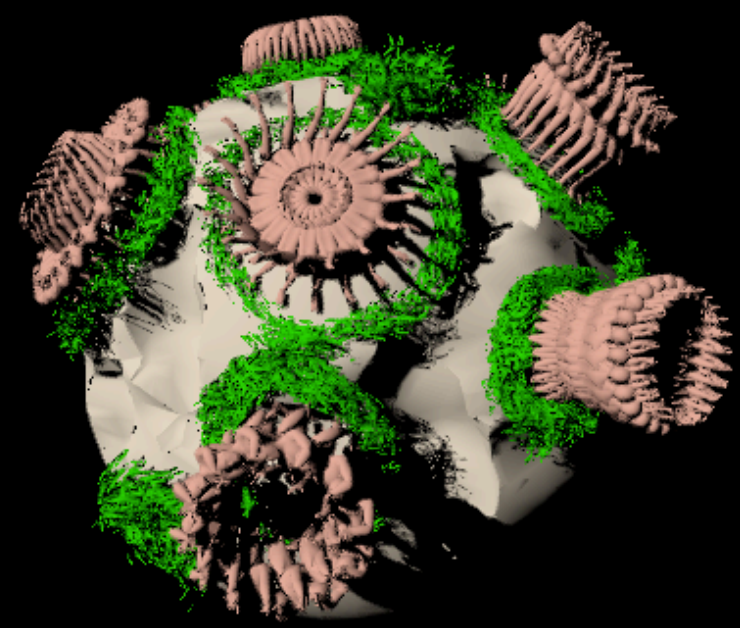

- $\theta x^{x}$

Figure 43. 3D model from Floratopia I (2013)

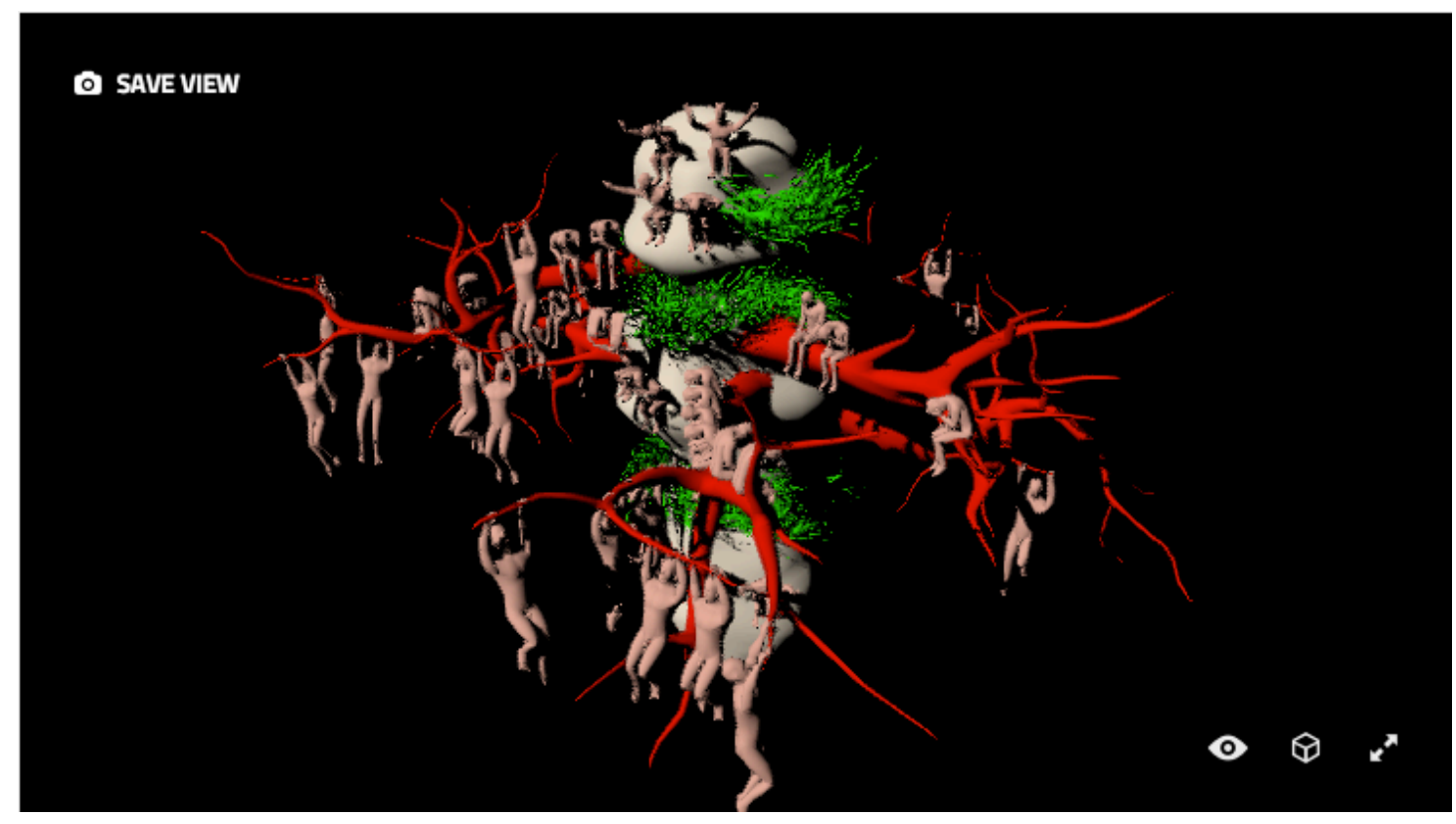

Figure 44. 3D model from Floratopia I (2013) 


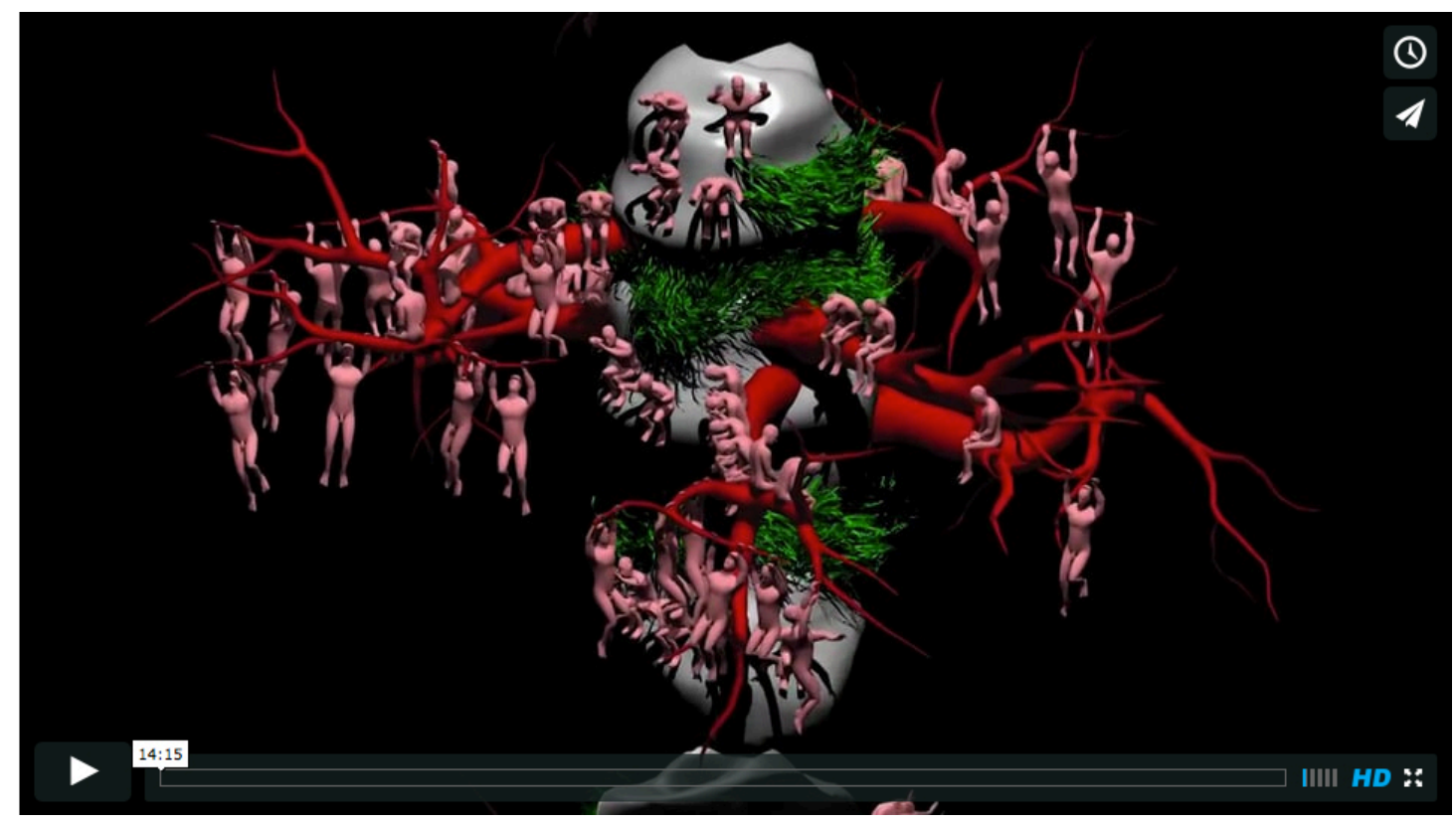

Figure 45. Floratopia I (2013)

\section{Creative constraints and the 'Database'}

Linda Candy considers that 'when we choose particular forms, materials and tools for our creative work, we are also choosing the kinds of constraints that will shape our process and its outcomes' (Candy, 2007, p. 266). Boden sees creative restrictions or limitations as charting 'a territory of structural possibilities which can be explored and perhaps transformed to give another one' (Boden, 2003, p. 94). And as previously mentioned, Malcom Le Grice contends that the engagement with the technologies of production are not 'neutral', characterising the process as a 'dialogue' with an 'embodied intellect'.

For Le Grice, the technology comes culturally and ideologically embedded; the artist produces the work as a dialogue 'in the space between the technical limits, the habits of application, and the attempt to break those constraints in the exploration of potentialities.' As such, he sees the 'technological base as integral to the construction of meaning' (Le Grice, 2001, p. 240). In particular the computer is characterised as 'the most sophisticated form of the embodiment of intellect in mechanical form yet devised.' Authorship of a work produced on the computer becomes a matter of tracking the interaction between the artist and the machine's cultural/social/psychological and ideological manifestations, through the work of art.

I am a user rather than a programmer of software so an immediate creative constraint is the limit of my own knowledge of the tool and my inability to manipulate code. However, as Wood proposes, the 'mediation of software' through the rhetoric of the user interface, which includes the more creative and 'user-friendly' Viewer window, together with the 'expanded arena' of the dialog box and drop-down menu, which promotes access to the underlying data structures of the 3D artefacts, enables an incremental process of knowledge acquisition for the user through practice. This engagement can also be characterised as working within what lan Bogost identifies as 
'possibility space' in relation to video games (Bogost, 2007), developing a flexible playlike exploration within a more rigid, albeit complex, super-structure.

\section{Conclusion}

As discussed, Manovich proposes a creative process with digital media structured around the idea of the database, which he positions in opposition to conventional linear narrative. In his words:

many new media objects do not tell stories; they do not have a beginning or end; in fact, they do not have any development, thematically, formally, or otherwise that would organize their elements into a sequence. Instead, they are collections of individual items, with every item possessing the same significance as any other...They appear as collections of items on which the user can perform various operations. (Manovich, 2001, p. 218)

He models the creation of a digital media work as the 'construction of an interface to a database...the interface [providing] access to an underlying database.' So rather than fashioning a unique work of art 'within a particular medium' where interface and data are one, in 'new media, the content of the work and the interface are separated. It is therefore possible to create different interfaces to the same material' (Manovich, 2001, p. 227). Elements can be composed and recomposed, duplicated, altered, retrieved and deleted non-destructively, representing a shift from creation to selection.

What I recognise in this dynamic between 'creative' user and complex software tool in my own incremental process of engagement and expertise with Autodesk Maya, are alignments between form and content, where my capabilities with, and employment of, generic and pre-set functions (loops, database structures of storage and retrieval), and intrinsic formal characteristics (Manovich's 'Modularity', 'Automation' and 'Variability') form a feedback loop with aesthetic and thematic concerns. My utilisation of a generic looped animated figure leads to questions as to the status of the animated body. What kind of 'life' does this animated loop create in the space between the animate and the inanimate, between automata (devices that move by themselves) and simulacra (devices that simulate other things)?

This figure is essentially passive and annulled, where gesture does not follow thought or emotion, but instead is generated zombie-like by another's will. This recalls Roger Cardinal's description of the animated film as something which 'enacts the lie of breathing life into what is dead or has never been alive' (Hames, 1995, p. 89). It echoes Alan Cholodenko's remark that

Animation always has something of the inanimate about it...a certain inanimateness that both allows and disallows animation... And this would mark the always already returned of the ghost, the zombie, and the dead in us lifedeath. (Cholodenko, 1993, pp. 28-29)

Finally, I turn to animator Robert Breer's interview comments in the documentary film on his work 'Robert Breer: The 'five \& dime' animator ' (Griffiths, 1985). His observations on metamorphic transformation in relation to the condition of the loop and 
its inability to achieve resolution, or perhaps the illusion that it creates of some kind of perpetual state of onward motion are apt:

...time doesn't move forward, things are going, but sideways, obliquely, down and backwards, not necessarily ahead. The sense of motion is the issue. That idea seems hard to defend, because our locomotion drives us forward with our faces looking at new things. But since that movement is toward oblivion, in my philosophy anyhow, it might as well be backward. It's a delusion to think you are getting anywhere. (Breer, 1985)

My works can be seen as existing in a perpetual state of 'nowness'. There is motion but not necessarily progression. The database as a creative tool allows for the paradoxical expression of a sense of motion and activity which is also profoundly inert and arrested. The retrieval and mutable configuration and re-configuration of set-inmotion elements is compulsively busy, but is ultimately a closed system, subject to the repetition compulsion of the loop, always returning and repeating, but retaining a mesmerising and habitual fascination. 


\section{References}

Bishop, C. (2012, September). Digital divide: contemporary art and new media. Retrieved October 3, 2015, from https://artforum.com/inprint/issue=201207\&id=31944

Boden, M. A. (2003). The creative mind: myths and mechanisms (2nd ed). London; New York: Routledge.

Bogost, I. (2007). Persuasive games: the expressive power of videogames. Cambridge, Mass: MIT Press.

Candy, L. (2007). Constraints and Creativity in the Digital Arts. Leonardo, 40(4), 366-367.

Cholodenko, A. (Ed.). (1993). The Illusion of Life: Essays on Animation. Sydney: Power Institute of Fine Arts.

Fischer, L. (1989). Shot/Countershot: Film Tradition and Women's Cinema. Princeton, N.J: Princeton University Press.

Griffiths, K. (Producer), Griffiths, K. (Director), \& Breer, R. (Performer). (1985). Robert Breer: The 'five \& dime' animator. [Motion picture]. United Kingdom: Large Door Productions.

Hames, P. (Ed.). (1995). Dark alchemy: the films of Jan Švankmajer. Westport, Conn: Greenwood Press.

Hart, C. (2013). Beginning and End Games A Parable in 3D. Cultural Politics, 9(1), 86-94. http://doi.org/10.1215/17432197-1907190

Hart, C., \& Clarke, R. (2012). The Real-Fake: Simulation Technology After Photography | Lamar Dodd School of Art. Retrieved October 4, 2015, from http://art.uga.edu/galleries/exhibitions/video-invitational

Hart, C., Clarke, R., \& Rees, M. (2011). The Aesthetics of the Fake: on-line catalog. Retrieved from http://www.claudiahart.com/theory/theorydocs/TheEstheticsOfTheFake.pdf

Harvey, N. (2005). The art of outsourcing [Many successful artists are working with technicians who contribute skill, time and experience to the final work. Paper in Handmade: The New Labour. Murray, Kevin (ed.).]. Artlink, 25(1), 15.

Le Grice, M. (2001). Experimental cinema in the digital age. London: British Film Institute.

Manovich, L. (2001). The language of new media. Cambridge, Mass: MIT Press.

McGowan, C., \& McCullaugh, J. (1995). Entertainment in the cyber zone. Random House Electronic Pub. 
Muybridge, E. (1884). Eadweard Muybridge: Man ascending stairs. 1884-85.

Retrieved from

https://commons.wikimedia.org/wiki/File:Muybridge_ascending_stairs.jpg

Muybridge, E. (2004). Animated sequence of a man ascending stairs, photos taken by Eadweard Muybridge in 1884-85. Retrieved from https://commons.wikimedia.org/wiki/File:Muybridge_ascending_stairs_animat ed_2.gif

Muybridge, Eadweard. (1887). A man walking. Photogravure after Eadweard Muybridge, 1887. [Photogravure]. Retrieved from https://commons.wikimedia.org/wiki/File:A_man_walking._Photogravure_after _Eadweard_Muybridge,_1887._Wellcome_V0048615.jpg

Theweleit, Klaus. (1992). Circles, Lines and Bits. In Crary, Jonathan \& Kwinter, Sanford (Eds.), Incorporations. New York, NY: Zone.

Wood, A. (2015). Software, animation and the moving image: what's in the box? Basingstoke, Hampshire, UK; New York, NY: Palgrave Macmillan.

\section{List of Figures}

Figure 1. Utopia I (2011) by Gregory Bennett. https://vimeo.com/44791389 ............. 3

Figure 2. Utopia II (2012) by Gregory Bennett. https://vimeo.com/45037300 ............ 4

Figure 3. Autodesk Maya user-interface screenshot ........................................... 7

Figure 4. Video clip of animated run cycle by Gregory Bennett (2004).................... 8

Figure 5. Video clip of animated walk cycle by Gregory Bennett (2009) ................... 9

Figure 6. A man walking. Photogravure after Eadweard Muybridge, 1887.(Muybridge, Eadweard, 1887). Wellcome Library, London. Wellcome Images. Copyrighted work available under Creative Commons Attribution only licence CC BY

4.0 http://creativecommons.org/licenses/by/4.0/

Figure 7. Eadweard Muybridge: Man ascending stairs. 1884-85. (Muybridge, 1884).

Public domain image. 10

Figure 8. Animated sequence of a man ascending stairs, photos taken by Eadweard Muybridge in 1884-85. (Muybridge, 2004). Public domain image.

Figure 9. Video clip of animated ascending/descending figures by Gregory Bennett11

Figure 10. 3D model of staircase and figures.

https://sketchfab.com/models/b9c8cd319b8f 4791837826ad467cf72d 11 
Figure 11. 3D models of staircase and

figures. https://sketchfab.com/models/fdd8382595e 24606826182dd299f5570 ….... 12

Figure 12. Video clip from Apokalypolis I (2013) by Gregory Bennett..................... 12

Figure 13. A phenakistoscope disc by Eadweard Muybridge (1893). Public domain image.

Figure 14. A phenakistoscope disc by Eadweard Muybridge (1893) - animated gif.

Public domain image.

Figure 15. 3D geometric mesh using polygon modelling.

https://sketchfab.com/models/5a4ac541da844d13a9aa0a63abe9579b

Figure 16. 3D model showing skeleton and animation control rig.

https://sketchfab.com/models/628895910cf54e6993bff1ad867c6f4d

Figure 17. 3D model showing skeleton and animation control

rig. https://sketchfab.com/models/c6dc86e2de4d4183ad0386a829109246. 15

Figure 18. Maya interface screenshot of 3D character model and rig 15

Figure 19. 3D modeling and rigging screenshots. 16

Figure 20. Screenshots of animated walk cycle. 16

Figure 21. Animated walk cycle. 17

Figure 22. Video clip of 3D modelling, rigging and animating process. 17

Figure 23. Video clip of Autodesk Maya interface showing animated walk cycle and Graph Editor

Figure 24. Video clip of Autodesk Maya interface showing work process. 19

Figure 25. Video clip of Autodesk Maya interface showing work process 20

Figure 26. Video clip of 3D rendered walk cycle tests 20

Figure 27. Screenshots of 3D work process. 21

Figure 28. Screenshots of 3D work process 21

Figure 29. Screenshots of 3D work process. 22

Figure 30 . Screenshots of 3D work process 22

Figure 31. Utopia I (2011) layout 23

Figure 32. Utopia I (2011) layout. 23

Figure 33. Utopia I (2011) by Gregory Bennett. https://vimeo.com/44791389 24

Figure 34. 3D model from Utopia IV (2013).

https://sketchfab.com/models/83de4471c840466b802856b13ded060a 
Figure 35. 3D model from Utopia IV (2013).

https://sketchfab.com/models/83de4471c840466b802856b13ded060a

Figure 36. 3D model from Utopia IV (2013).

https://sketchfab.com/models/41e9db18686242ee88b6d4955cc07e61

Figure 37. 3D model from Utopia IV (2013).

https://sketchfab.com/models/49b1f4eabb54460abf5b1d20f4e9e2bc... 26

Figure 38. 3D model from Utopia IV (2013).

https://sketchfab.com/models/02f8fd0d116a44468495fed3b306ca70 26

Figure 39. Utopia IV (2013) by Gregory Bennett. https://vimeo.com/72710217 ....... 27

Figure 40. 3D model from Dromosphere I (2013).

https://sketchfab.com/models/81dad92287054189b696dcc15376a2bc 27

Figure 41. 3D model from Dromosphere I (2013).

https://sketchfab.com/models/f6cff72fd409468cb2d02d48f1af1c87

Figure 42. Dromosphere I (2013) by Gregory Bennett. https://vimeo.com/78191627

Figure 43. 3D model from Floratopia I (2013).

https://sketchfab.com/models/c693c50e469945de8857a25e3fb38f19

Figure 44. 3D model from Floratopia I (2013).

https://sketchfab.com/models/e20aea51c3e34648b9e091feab92f178

Figure 45. Floratopia I (2013) by Gregory Bennett. https://vimeo.com/78199720 .... 30 


\begin{abstract}
About the Author
Gregory Bennett is a Senior Lecturer in the Digital Design Department, School of Art \& Design, AUT University, New Zealand, and a practicing artist who works with 3D animation, motion capture, projection mapping and interactive media. He has a Master of Fine Arts degree from the Elam School of Fine Arts, University of Auckland, New Zealand, and has been teaching at AUT University since 2005 where he established the first courses in motion capture. He is also Director of AUT's Motion Capture Lab and is currently involved with developing research at AUT around Motion Capture and Virtual Production in a range of areas including Dance, Performance, Fashion, Pedagogy, and Virtual Reality. He has presented both his creative practice and research at international new media conferences and festivals such as SIGGRAPH, ISEA, CURRENTS, and SIMULTAN. As an artist he has exhibited both nationally and internationally, including Australia, the USA, and Europe, and his work is represented in both public and private collections. He is currently represented by Two Rooms Gallery in Auckland.
\end{abstract}

\title{
Contact: $\quad$ gregorybennett@xtra.co.nz
}

AUT University Research Profile: http://www.aut.ac.nz/profiles/art--design/seniorlecturers/gregory-bennett

Gregory Bennett Artist website: http://www.gregorybennett.net/

Vimeo channel: https://vimeo.com/gregorywilliambennett

Youtube channel: https://www.youtube.com/user/gregorybennett12

Facebook page: https://www.facebook.com/gregorywilliambennett

Two Rooms Gallery Artist page: http://tworooms.co.nz/artists/gregory-bennett/ 


\section{The Journal of Creative Technologies (JCT)}

https://ctechjournal.aut.ac.nz

ISSN: $2230-2115$

Colab, Auckland University of Technology, New Zealand

Creative Commons Attribution 4.0 International License (CC-BY)

All articles published in The Journal of Creative Technologies (JCT) from Issue 4 onwards are licensed under a Creative Commons Attribution 4.0 International License (CC-BY). The copyright of the material remains with the author(s), and third-parties are granted permission to use, shared, and adapted the material, provided the original work is appropriately attributed.

The Journal of Creative Technologies (JCT) is an online, open access, peer-reviewed journal for the publication of research and innovation about new technologies, creative practices, and critical theories. The journal aims to explore applied, methodological and theoretical perspectives on emergent technological platforms and strategies through thematically focused issues.

$J C T$ is a research communication platform published by Colab at the Faculty of Design and Creative Technologies, Auckland University of Technology. 